\title{
Economic determinants of oil futures volatility: a term structure perspective
}

Article

Accepted Version

Creative Commons: Attribution-Noncommercial-No Derivative Works 4.0

Kang, B., Nikitopoulos, C. S. and Prokopczuk, M. (2020) Economic determinants of oil futures volatility: a term structure perspective. Energy Economics, 88. 104743. ISSN 0140-9883 doi: https://doi.org/10.1016/j.eneco.2020.104743 Available at https://centaur.reading.ac.uk/90002/

It is advisable to refer to the publisher's version if you intend to cite from the work. See Guidance on citing.

To link to this article DOI: http://dx.doi.org/10.1016/j.eneco.2020.104743

Publisher: Elsevier

All outputs in CentAUR are protected by Intellectual Property Rights law, including copyright law. Copyright and IPR is retained by the creators or other copyright holders. Terms and conditions for use of this material are defined in the End User Agreement.

\section{www.reading.ac.uk/centaur}

\section{CentAUR}

Central Archive at the University of Reading

Reading's research outputs online 


\title{
Economic determinants of oil futures volatility:
}

\section{A term structure perspective}

\author{
Boda Kang ${ }^{\mathrm{a}}$, Christina Sklibosios Nikitopoulos ${ }^{\mathrm{b}}$, Marcel Prokopczuk ${ }^{\mathrm{c}}$ \\ ${ }^{a}$ Lacima Group, \\ 56 Pitt St, Sydney NSW 2000, Australia \\ ${ }^{b}$ University of Technology Sydney, \\ Finance Department, UTS Business School, \\ PO Box 123 Broadway NSW 2007, Australia \\ ${ }^{c}$ Leibniz University Hannover, \\ Koenigsworther Platz 1, 30167, \\ Hannover, Germany
}

March 1, 2020

\begin{abstract}
To assess the economic determinants of oil futures volatility, we firstly develop and estimate a multi-factor oil futures pricing model with stochastic volatility that is able to disentangle long-term, medium-term and short-term variations in commodity markets volatility. The volatility estimates reveal that in line with theory, the volatility factors are unspanned, persistent and carry negative market price of risk, while crude oil markets are becoming more integrated with financial markets. After 2004, short-term volatility is driven by industrial production, term and credit spreads, the S\&P 500 and the US dollar index, along with the traditional drivers including hedging pressure and VIX. Medium-term volatility is consistently related to open interest and credit spreads, while after 2004 oil sector variables such as inventory and consumption also impact this part of the term structure. Interest rates mostly matter for long-term futures price volatility.
\end{abstract}

Keywords: oil market, volatility, term structure, macro-economy JEL: G12, G13, C58, Q40,

Email addresses: boda.kang@lacimagroup.com (Boda Kang), christina.nikitopoulos@uts.edu.au (Christina Sklibosios Nikitopoulos), prokopczuk@fmt.uni-hannover.de (Marcel Prokopczuk) 


\section{Introduction}

The volatility of oil markets has drawn the attention not only of producers and consumers but also of financial investors. Motivated by the traditional low negative correlation between equity and commodity markets (Gorton and Rouwenhorst (2006)), commodity derivatives have been used as risk diversification tools and form substantial components of investment portfolios. Yet, more recent research detects a stronger correlation and substantial volatility spillovers between equity and commodity markets (Chiang, Hughen, and Sagi (2015) and Basak and Pavlova (2016)) giving grounds for analysing the nature and the drivers of commodity futures volatility. Undoubtedly following the financialisation of commodity markets, commodity derivatives markets have witnessed a substantial increase in trading volume and have become popular investment choices (with the leading commodity being crude oil). This is subsequently reflected in the rising volatility of oil futures markets (and of commodity futures markets in general) and has led to deliberations as to what extent commodity specific factors and/or economic conditions are the driving forces of oil volatility.

Disentangling the drivers of volatility in oil futures markets is important for several reasons. The volatility of oil futures markets is the result of a complex set of information interactions in the commodity's spot market (including the fundamental drivers of demand and supply), in the dynamics of the futures markets, and in the global and regional political and economic conditions. It is also critical to take into account the term structure of the oil futures volatility, given the varying exposure of this term structure to economic variables. Further, volatility has crucial implications for macro-economic stability. The inherent feature of uncertainty is reflected in investment curtailing, impediments on economic growth, and impacts key economies that rely heavily on oil. It is argued that for the macro-economy, the level of volatility (rather than the prices) in the oil sector matters the most (Chiang et al. (2015)). The oil market is directly affected by the impact of the volatility on the demand for storage, the cost of production, and the investments in production and transportation, while for institutional investors and hedge funds, volatility presents an opportunity to capitalize 
on risk. Commodity derivatives evaluation and hedging is also closely associated to the volatility of the oil futures market.

This paper aims to quantify the oil futures volatility and assess its sensitivity to commodity specific shocks and news from the macro-economy. We introduce a new modelling framework to represent the term structure of the volatility and identify the determinants of estimated latent volatility factors. Embedding an economic meaning to these latent volatility factors allows us to better understand the oil futures volatility. We find new evidence regarding the determinants of the term structure of this volatility that untangles the contributions of macro-economic and oil sector variables. While extensive literature has been dedicated to investigating the determinants of commodity spot and futures prices, and the volatility of spot commodity prices (e.g. Schwartz and Smith (2000), Pindyck (2001), Dempster, Medova, and Tang (2012), Morana (2013), Hitzemann (2016) and Heath (2019)), this is the first study to analyse the term structure of the oil futures volatility. Our modelling framework is capable of simultaneously fitting futures prices and their volatilities of any maturity, a feature that is not attainable with the commonly used pure spot price models. By using an equilibrium model, Chiang et al. (2015) model and estimate factors associated with the term structure of the oil volatility but they focus only on the impact of key economic indicators on oil prices and risk factors, while allowing only one risk factor to capture the unspanned characterisation of the volatility.

We firstly propose a general multi-factor model for commodity futures with stochastic volatility that systematically captures the volatility term structure via three factors for shortend, shape, and long-end effects and accommodates the important features of unspanned volatility and time varying risk premia. While being able to capture all these features, our stochastic volatility model remains tractable as it provides affine representations for futures prices and quasi analytical formulas for futures option prices. We use thirty years of data of crude oil derivatives prices split into two sub-periods, marked by the initiation of the financialisation of commodities in 2004, to estimate the model. As expected, we find that 
the volatility factors are highly persistent and unspanned. We also provide new evidence indicating that short-term volatility is less spanned by futures contracts compared to the longer maturity volatility factors.

The characteristics of the volatility factors change over time. We identify perceptible changes in the nature of these volatility factors after 2004. Correlations between innovations in futures prices and the shape volatility factor have changed from positive to negative, while similar observations can be made for the market prices of futures price risk. These changes support the notion that since 2004 crude oil markets have been more integrated with classical financial markets (Nikitopoulos, Squires, Thorp, and Yeung (2017), Baur and Dimpfl (2018)), highlighting the importance of the re-evaluation of the economic determinants of oil futures volatility over this period.

The key objective of the study is to understand the economic determinants of the term structure of crude oil futures price volatility. To this end, we analyse the relation of the estimated oil futures volatility factors with a dataset of seventeen economic variables, categorised by variables in the oil sector, from macro-economic conditions and from financial markets. We find that the short-term volatility factor is associated with hedging pressure and the VIX, while the medium-term volatility factor is linked to inflation, industrial production, the VIX and credit spreads. Long-term volatility is mainly driven by interest rates. In light of Basu and Miffre (2013), Chiang et al. (2015), Basak and Pavlova (2016), and Heath (2019), these results are consistent with demand for hedging, the VIX and economic activity (captured by inflation and industrial production) being the key drivers of oil risk factors. The paper further suggests that, hedging pressure has an immediate effect on the oil futures volatility, economic activity has a longer term effect, and the VIX is a persistent determinant, underscoring further the importance of oil volatility to the general market uncertainty.

We also find that the determinants of the oil futures volatility vary over time, in terms of both commodity specific shocks and news from the macro-economy. Since 2004, short- 
term volatility is not only sensitive to hedging pressure and the VIX, but also to the futures spreads, industrial production, credit spreads and the US dollar index. Additional to the above-mentioned macro-economic variables, since 2004 medium-term volatility is also determined by oil market specific variables such as inventory, consumption and open interest. However, for the long-term volatility factor the key determinant remains interest rates, but their positive relation reverses after 2004. As documented by an extensive literature, including Kilian and Hicks (2013), Cheng and Xiong (2014) and Kilian (2016), the impact of the financialisation of the commodity markets, the Global Financial Crisis (GFC), and the significant structural changes in crude oil markets (e.g. lift of export ban and the expansion of the shale market) have played a role in explaining these changes.

This paper bridges two main strands of literature. The first strand addresses the modelling of commodity derivatives markets with affine representations of state variables. Even though these state variables are typically unobservable, they allow us to calibrate the models to derivatives market prices. Such studies include Schwartz (1997), Schwartz and Smith (2000), Casassus and Collin-Dufresne (2005), Paschke and Prokopczuk (2010), Dempster et al. (2012), Casassus, Liu, and Tang (2013), Back, Prokopczuk, and Rudolf (2013), and Prokopczuk and Wu (2016), which mostly deal with analysing commodities futures markets and assume deterministic volatility. Extensions to account for stochastic volatility / stochastic interest rates / jumps / seasonality have been considered, such as Trolle and Schwartz (2009), Chiarella, Kang, Nikitopoulos, and Tô (2013), Arismendi, Back, Prokopczuk, Paschke, and Rudolf (2016), Cheng, Nikitopoulos, and Schögl (2018), Cortazar, Lopez, and Naranjo (2017), Schneider and Tavin (2018) and Da Fonseca and Ignatieva (2019) which calibrate to both futures and options markets and are able to study the volatility of these markets. The dimensionality of the models as well as the features of the volatility comprise the main points of investigation. We complement this literature by proposing a model for the volatility term structure that contains three unspanned volatility factors: a short-end factor, a shape factor and a long-end factor. The short-end factor captures the short-term variations, 
while the shape and long-end factors have the ability to capture medium- and long- term variations in a flexible way. The second strand studies the relation between commodity spot or future prices, and spot volatility with economic variables by using equilibrium models (Casassus et al. (2013), Chiang et al. (2015), Gao, Hitzemann, Shaliastovich, and Xu (2017), Heath (2019)), or VaR models (Alquist and Kilian (2010), Symeonidis, Prokopczuk, Brooks, and Lazar (2012), Silvennoinen and Thorp (2013), Kilian and Murphy (2014), Cheng and Xiong (2014), Anzuini, Pagano, and Pisani (2015), Kilian (2016), Prokopczuk, Stancu, and Symeonidis (2019), Hollstein, Prokopczuk, and Wuersig (2019)). Typically, short-term price variations are associated with demand variables in the physical markets and trading variables in the futures markets. Medium-term price variations are usually attributed to business cycle conditions and demand and trading variables. Most of the above studies do not analyse the term structure of the oil futures volatility, mainly due to the inherent issues associated with modelling the entire volatility term structure.

The remainder of the paper is structured as follows: The data are described in Section 2. Section 3 outlines the commodity futures pricing model that admits solutions for affine futures prices and quasi-analytical option prices on commodity futures. Section 4 presents the results of the model estimation, and analyses the characteristics of the term structure of the crude oil futures volatility. A detailed discussion of the determinants of the three volatility factors is presented in Section 5. In Section 6, a variety of robustness tests are presented. Section 7 concludes.

\section{Data}

\subsection{Crude oil futures and options}

We employ a large dataset of daily WTI crude oil futures and option prices provided by the Chicago Mercantile Exchange (CME). ${ }^{1}$ Figure 1.a depicts the crude oil futures prices for

\footnotetext{
${ }^{1}$ Although the introduction of shale oil and transportation issues caused a recent divergence between WTI and Brent crude oil prices, the WTI crude oil market remains a reliable representation of global oil market conditions in light of the changes to the benchmark definition (Kilian (2016)).
} 


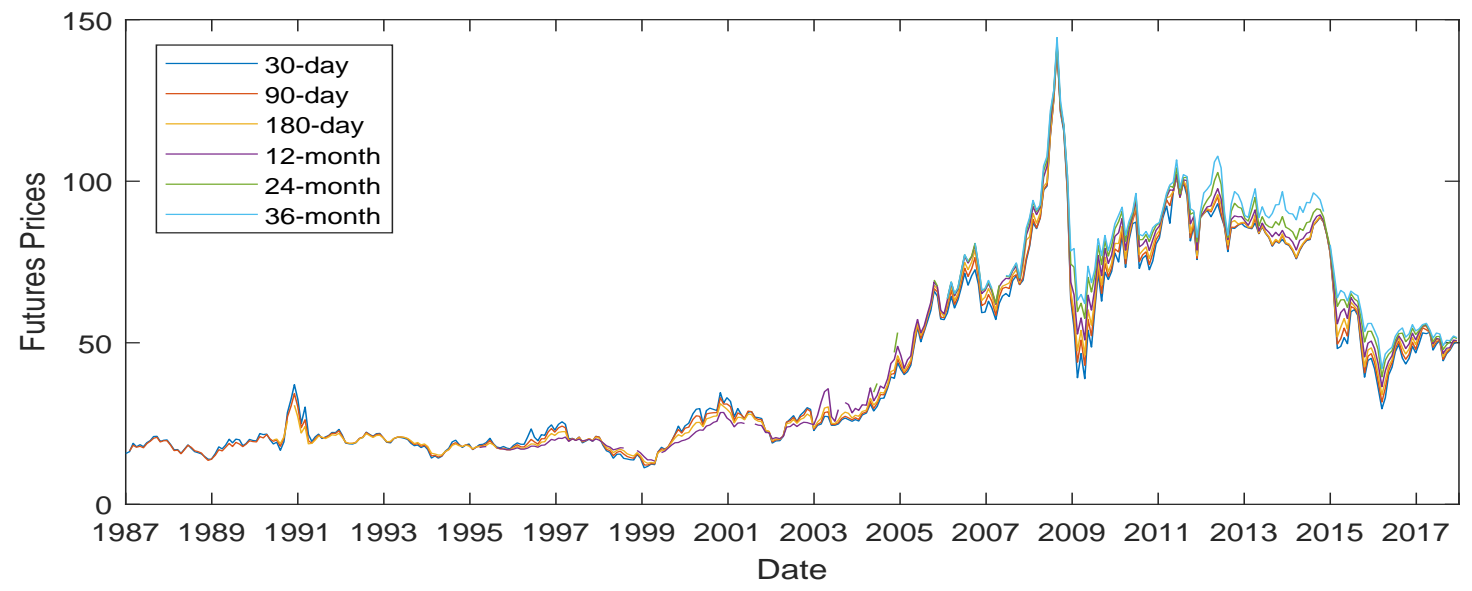

1.a: Futures prices

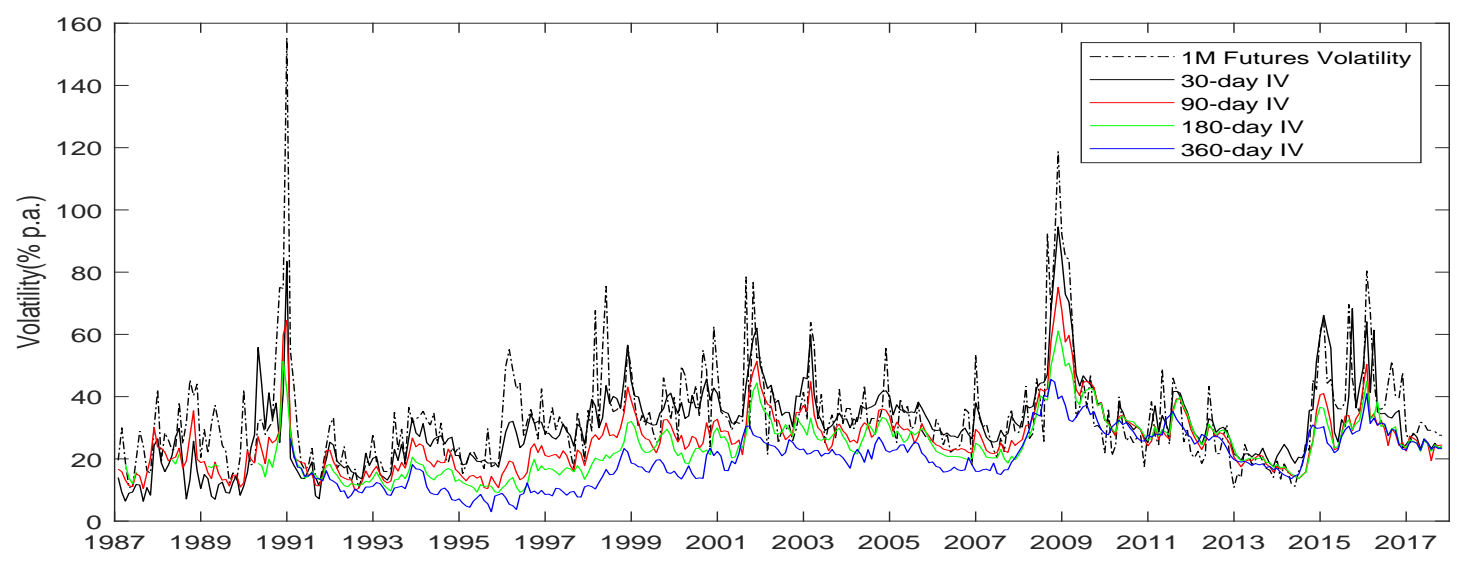

1.b: One-month futures price volatility and 30-day, 90-day, 180-day and 360-day at-the-money implied volatility

Figure 1: Crude oil futures prices and volatility

The figure shows the time series of crude oil futures prices and their volatility. Panel 1.a displays the prices of crude oil futures contracts of selected maturities and panel 1.b displays the monthly average annualized standard deviation of daily log-returns of the one-month futures price and the mean of the 30-day, 90-day, 180-day and 360-day implied volatility, from January 1987 to October 2017.

various maturities over our sample period from January 1987 to October 2017. Figure 1.b graphs the annualized standard deviation of daily log-returns of the one-month futures prices (over a month $)^{2}$ and the implied volatilities of at-the-money call and put futures options for 30-day, 90-day, 180-day and 360-day maturities. ${ }^{3}$ One can observe that the oil futures prices have experienced large movements and volatility.

\footnotetext{
${ }^{2}$ It is customary to consider the one-month futures price as an approximation of the crude oil spot price.

${ }^{3}$ The European style implied volatilities have been inferred from the American style WTI futures options by using the Barone-Adesi and Whaley (1987) approximation and the Black (1976) formula.
} 

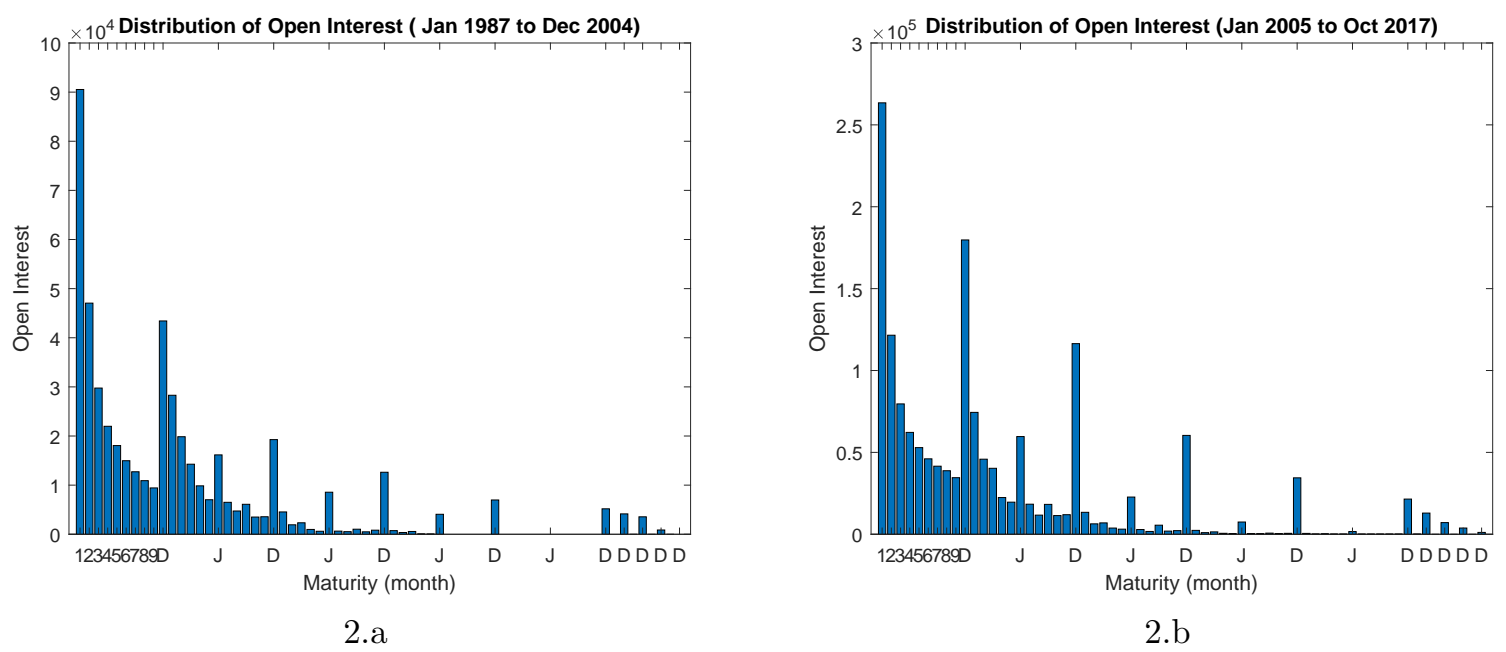

Figure 2: Liquidity of crude oil futures contracts

The figure shows the average open interest of futures contracts for different maturities, from January 1987 to December 2004 in Figure 2.a, and from January 2005 to October 2017 in Figure 2.b.

Looking at the descriptive statistics for the returns of oil futures prices for selected maturities reported in Table 1, it is evident that there is an overall increase in the means and the standard deviations of these returns since 2004 (e.g. means (standard deviations) have increased from $14.93 \%$ (28.01\%) to $25.22 \%$ (31.72\%) for the 3-month futures contracts and from $11.83 \%(25.71 \%)$ to $31.27 \%(29.88 \%)$ for 6-month futures contracts). Typically, shorter maturity contracts have higher means and standard deviations compared to longer maturity contracts before 2004, while a mixed behavior in the means is evident after $2004{ }^{4}$

Due to the large number of daily available futures contracts, we select the most liquid futures contracts for our study (liquidity measured by the open interest). Figure 2 shows the average liquidity before and after 2004. As contracts close to expiry have very low liquidity, we exclude contracts with less than 14 days to maturity. The first seven monthly contracts are used, followed by the five contracts that have March, June, September or December expiration months. Additionally, we include the next five December contracts. Therefore

\footnotetext{
${ }^{4}$ Crude oil futures markets have experienced significant variation over the last 30 years, which have drastically impacted the characteristics of the oil futures returns. For example Chiarella et al. (2013) document the remarkable changes in the descriptive statistics for returns of oil futures prices over four sub-periods between 1990 and 2010 .
} 
Table 1: Descriptive statistics of futures prices The table presents descriptive statistics for daily $\log$ returns of 3-month, 6-month, 12-month and 24-month futures prices between January 1987 and October 2017 and the two sub-periods 1987-2004 and 2005-2017. Means and standard deviations are expressed in annualized percentage units. The descriptive statistics of daily log returns for 24-month futures prices are omitted in the sub-period 1987-2004 due to the low liquidity of contracts with longer maturities.

\begin{tabular}{lcccc}
\hline Maturity & 3-month & 6-month & 12-month & 24-month \\
\cline { 2 - 5 } Period: 1987-2017 & & & & \\
Mean & 19.23 & 20.90 & 24.11 & 28.76 \\
Standard Deviation & 29.62 & 27.74 & 27.00 & 25.85 \\
Kurtosis & 17.86 & 9.61 & 3.16 & 3.06 \\
Skewness & -1.03 & -0.59 & -0.13 & 0.10 \\
& & & & \\
Period: 1987 -2004 & & & & \\
Mean & 14.93 & 11.83 & 24.55 & \\
Standard Deviation & 28.01 & 25.71 & 26.71 & \\
Kurtosis & 33.53 & 18.70 & 3.24 & \\
Skewness & -2.25 & -1.58 & -0.44 & \\
& & & & \\
Period: 2005-2017 & & & & \\
Mean & 25.22 & 31.27 & 23.81 & 28.76 \\
Standard Deviation & 31.72 & 29.88 & 27.20 & 25.85 \\
Kurtosis & 3.96 & 3.40 & 3.11 & 3.06 \\
Skewness & 0.13 & 0.12 & 0.07 & 0.10 \\
\hline
\end{tabular}

the number of crude oil futures contracts used on a daily basis ranges between 7 and 17 . We select the options contracts that have the futures mentioned above as underlying. We consider six moneyness intervals for each maturity, namely 0.86-0.90, 0.91-0.95, 0.95-1.00, 1.01-1.05, 1.06-1.10, and 1.11-1.15..$^{5}$ After this selection, the number of options selected per day are 50-80 for the period 1987-2004 and 109-245 for the period 2005-2017.

In our empirical investigations, we also split our dataset into two sample periods. Other empirical studies have found a structural break around 2004 (Irwin and Sanders (2011), Tang and Xiong (2012) and Hamilton and Wu (2014)), thus we choose to split the sample in December 2004 which marks the initiation of the financialisation of the commodity markets.

\subsection{Economic variables}

We employ economic variables that we categorise as oil sector variables, macro-economic conditions/business cycle variables, and financial market variables. ${ }^{6}$

The crude oil sector data are obtained from the US Energy Information Administration,

\footnotetext{
${ }^{5}$ Moneyness is defined as the ratio between option strike and the price of the underlying futures contract. We concentrate on OTM and ATM options for two reasons: these are the most liquid contracts and OTM options have lower early exercise approximation errors.

${ }^{6}$ The online Appendix provides a detailed account of the dataset used in the analysis and justifies the selection of each variable.
} 
Table 2: Descriptive Statistics The table reports the descriptive statistics for the monthly series (end of the month observation) of the economic variables used in the analysis. US inventory, consumption, and open interest are expressed in logarithms. The remaining variables are expressed in levels. Data series span from January 1987 to October 2017, with two sub-periods: January 1987 - December 2004 and January 2005 October 2017.

\begin{tabular}{|c|c|c|c|c|c|c|c|c|c|c|c|c|}
\hline Series & Mean & $\begin{array}{r}\text { Stand. Dev. } \\
\text { January } 1987\end{array}$ & $\begin{array}{c}\text { Skewness } \\
\text { October } 2017\end{array}$ & Kurtosis & Mean & $\begin{array}{r}\text { Stand. Dev. } \\
\text { January } 1987 \text { - }\end{array}$ & $\begin{array}{c}\text { Skewness } \\
\text { December } 2004 \\
\end{array}$ & $4^{\text {Kurtosis }}$ & Mean & $\begin{array}{r}\text { Stand. Dev. } \\
\text { January } 2005 \text { - }\end{array}$ & $\begin{array}{c}\text { Skewness } \\
\text { October } 2017 \\
\end{array}$ & Kurtosi: \\
\hline $\begin{array}{l}\text { Oil-sector Variables } \\
\text { US Inventory (log) }\end{array}$ & 5.977 & 0.044 & 0.615 & 2.374 & 5.945 & 0.015 & 0.017 & 2.984 & 6.023 & 0.026 & 0.922 & 2.916 \\
\hline Consumption $(\log )$ & 4.274 & 0.030 & -0.349 & 2.214 & 4.262 & 0.032 & 0.134 & 1.819 & 4.291 & 0.018 & 0.326 & 2.323 \\
\hline 12-month futures spreads & -0.012 & 0.105 & 0.263 & 3.721 & -0.052 & 0.098 & 0.240 & 3.138 & 0.043 & 0.087 & 1.025 & 5.106 \\
\hline Open interest $(\log )$ & 5.801 & 0.327 & 0.018 & 1.784 & 5.555 & 0.165 & -0.567 & 2.819 & 6.148 & 0.111 & -0.417 & 3.145 \\
\hline Hedging Pressure & 0.046 & 0.099 & 0.491 & 2.846 & -0.004 & 0.067 & -0.111 & 3.058 & 0.115 & 0.094 & 0.126 & 1.853 \\
\hline \multicolumn{13}{|l|}{ Macro-economic conditions } \\
\hline Treasury bond yield spread & 1.782 & 1.129 & -0.225 & 2.070 & 1.751 & 1.182 & -0.096 & 1.819 & 1.827 & 1.054 & -0.445 & 2.590 \\
\hline Consumer Price Index & 185.950 & 39.369 & -0.025 & 1.746 & 156.940 & 22.168 & -0.091 & 1.999 & 226.376 & 14.578 & -0.195 & 1.974 \\
\hline CFNAI & -0.121 & 0.795 & -1.976 & 10.311 & 0.012 & 0.665 & -0.574 & 3.017 & -0.306 & 0.916 & -2.504 & 10.696 \\
\hline \multirow{2}{*}{\multicolumn{13}{|c|}{$\begin{array}{l}\text { Industrial variables } \\
\text { Finanction }\end{array}$}} \\
\hline & & & & & & & & & & & & \\
\hline FF size & 0.027 & 1.285 & 0.254 & 9.048 & -0.012 & 1.409 & 0.494 & 9.921 & 0.080 & 1.091 & -0.388 & 3.628 \\
\hline FF value & -0.038 & 1.281 & -0.637 & 10.199 & 0.068 & 1.204 & 0.192 & 4.431 & -0.185 & 1.371 & -1.358 & 14.305 \\
\hline Mom & 0.117 & 0.890 & 0.106 & 10.621 & 0.139 & 0.694 & 0.959 & 8.971 & 0.086 & 1.109 & -0.146 & 8.659 \\
\hline S\&P 500 returns & 0.002 & 0.023 & -0.774 & 6.669 & 0.001 & 0.024 & -0.476 & 6.593 & 0.003 & 0.021 & -1.300 & 6.755 \\
\hline VIX level & 19.392 & 7.633 & 1.913 & 9.675 & 19.871 & 6.141 & 0.621 & 2.921 & 18.833 & 9.060 & 2.367 & 10.427 \\
\hline 3-month Treasury rates & 3.256 & 2.606 & 0.206 & 1.841 & 4.719 & 2.084 & -0.140 & 2.413 & 1.218 & 1.754 & 1.273 & 2.999 \\
\hline US dollar index & 87.859 & 9.708 & 0.132 & 2.558 & 93.264 & 7.305 & 0.599 & 2.831 & 80.327 & 7.340 & 0.462 & 2.038 \\
\hline Credit spreads & 0.966 & 0.383 & 3.108 & 16.972 & 0.872 & 0.228 & 0.600 & 2.291 & 1.098 & 0.500 & 2.647 & 10.728 \\
\hline
\end{tabular}

the CME and the US Commodity Futures Trading Commission (CFTC). We use five oil sector variables, including US crude oil inventory, crude oil consumption, the 12-month futures spread, the open interest of all oil futures traded at CME and hedging pressure.

The macro-economic conditions/business cycle variables are compiled from FRED. ${ }^{7}$ We include the following four variables: Treasury bond yield spreads, Consumption Price Index (CPI), Chicago Fed National Activity Index (CFNAI), and Industrial Production (ID). Most of the financial variables are also compiled from FRED (except VIX which is collected from Bloomberg) and include the S\&P 500 index returns, the Fama-French size and value factors, momentum, the VIX, 3-month Treasury rates, the US dollar index, and credit spreads. Several of the macro-economic variables are not available at daily frequency, thus we investigate the relationships between oil futures volatility and the economic variables on a weekly and monthly basis. Since data on hedging pressure are available only on Tuesday, all weekly data have been recorded on Tuesday, while monthly data are compiled at the end of the month.

Summary statistics of the economic variables are reported in Table 2. Expected changes between the two sub-periods are reported including an increase in the mean of the open

\footnotetext{
${ }^{7}$ Federal Reserve Bank of St.Louis, see http://research.stlouis.gov/fred2/.
} 
interest, CPI, IP, S\&P 500 returns and credit spreads after 2004. Further, the mean of Treasury rates drops from $4.7 \%$ to $1.2 \%$ and the futures spread reverts from negative to positive, reflecting the extended periods of contango in oil futures markets since 2004, while the distributions of most of the economic variables are skewed and display higher kurtosis. The table with the results of the Augmented Dickey-Fuller unit root test is available in the online Appendix (Appendix A). For US inventory, CPI and IP we cannot reject the null hypothesis of a unit root, but we are able to do so for the detrended series. Thus in the analysis we consider the de-trended US inventory, the de-trended CPI and the de-trended IP. For crude oil consumption, the Treasury bond yield spreads, and the US dollar index we cannot reject the null hypothesis of a unit root (in levels and with trend), and thus we take the first differences for these series. ${ }^{8}$

\section{Modelling the futures price volatility}

A continuous time futures pricing model that encompasses a three-factor stochastic volatility is used to model the term structure of the volatility of the crude oil futures market. Our framework allows us to derive closed-form futures pricing equations and quasi-analytical price formulas for futures options.

\subsection{Commodity futures pricing model}

We assume a filtered probability space $\left(\Omega, \mathcal{A}_{T}, \underline{\mathcal{A}}, P\right), T \in(0, \infty)$ with $\underline{\mathcal{A}}=\left(\mathcal{A}_{t}\right)_{t \in[0, T]}$ which satisfies the usual conditions. ${ }^{9}$ The volatility in the commodity futures market is modelled via the three-dimensional stochastic process $\mathbf{V}=\left\{\mathbf{V}_{\mathbf{t}}, t \in[0, T]\right\}$. We denote as $S\left(t, \mathbf{V}_{\mathbf{t}}\right)$ the spot commodity price at time $t \geq 0$, and $F\left(t, T, \mathbf{V}_{\mathbf{t}}\right)$ the commodity futures price at time $t$, for delivery at time $T$, (for all maturities $T \geq t$ ). No-arbitrage arguments imply

\footnotetext{
${ }^{8}$ Even though some of these series are stationary in some sub-periods as shown in the online Appendix A, for consistency we run the analysis using these specifications.

${ }^{9}$ The usual conditions satisfied by a filtered complete probability space are: (a) $\mathcal{F}_{0}$ contains all the $P$-null sets of $\mathcal{F}$ and (b) the filtration is right continuous. See Protter (2004) for technical details.
} 
that the futures price is equal to the expected spot price under an equivalent risk-neutral probability measure $Q$ (see Duffie (2001)), namely

$$
F\left(t, T, \mathbf{V}_{\mathbf{t}}\right)=\mathbf{E}^{Q}\left[S\left(T, \mathbf{V}_{\mathbf{T}}\right) \mid \mathcal{A}_{t}\right]
$$

Consequently, the commodity futures price is a martingale under the risk-neutral measure and the commodity futures price process is described by a driftless stochastic differential equation under the risk-neutral measure. We further specify our three-factor model as follows

$$
\begin{aligned}
\frac{d F\left(t, T, \mathbf{V}_{\mathbf{t}}\right)}{F\left(t, T, \mathbf{V}_{\mathbf{t}}\right)} & =\sum_{i=1}^{3} \sigma_{i}\left(t, T, \mathbf{V}_{\mathbf{t}}\right) d W_{i}^{1}(t) \\
d V_{t}^{i} & =\mu_{i}\left(\nu_{i}-V_{t}^{i}\right) d t+\varepsilon_{i} \sqrt{V_{t}^{i}}\left(\rho_{i} d W_{i}^{1}(t)+\sqrt{1-\rho_{i}^{2}} d W_{i}^{2}(t)\right)
\end{aligned}
$$

where $W^{1}(t)$ and $W^{2}(t)$ are three-dimensional independent Wiener processes, and for $i=$ $1,2,3, W_{i}^{1}(t)$ and $W_{i}^{2}(t)$ are the $i^{t h}$ components of these two Wiener processes, respectively. The variance process $\mathbf{V}_{\mathbf{t}}=\left\{V_{t}^{1}, V_{t}^{2}, V_{t}^{3}\right\}$ is a three-dimensional Heston (1993) type process where $\mu_{i}, \nu_{i}$, and $\varepsilon_{i}$ are constants for $i=1,2,3$. In addition, the correlation coefficients $\rho_{i}$ are

constants for $i=1,2,3$ and determine the extent to which the volatility risk can be hedged (spanned) by futures contracts.

\subsection{Volatility term structure}

We assume that the $\underline{\mathcal{A}}$-adapted futures price volatility processes $\sigma_{i}\left(t, T, \mathbf{V}_{\mathbf{t}}\right)$ have the following functional forms, for all $T>t$,

$$
\begin{aligned}
& \sigma_{1}\left(t, T, \mathbf{V}_{\mathbf{t}}\right)=\kappa_{1} e^{-\eta_{1}(T-t)} \sqrt{V_{t}^{1}} \\
& \sigma_{2}\left(t, T, \mathbf{V}_{\mathbf{t}}\right)=\kappa_{2}(T-t) e^{-\eta_{2}(T-t)} \sqrt{V_{t}^{2}} \\
& \sigma_{3}\left(t, T, \mathbf{V}_{\mathbf{t}}\right)=\kappa_{3}\left(1-e^{-\eta_{3}(T-t)}\right) \sqrt{V_{t}^{3}}
\end{aligned}
$$

with $\kappa_{i}>0$ and $\eta_{i}>0$, for $i=1,2,3$. 
The short-end volatility factor $\sigma_{1}\left(t, T, \mathbf{V}_{\mathbf{t}}\right)$ predominantly gauges the volatility of the short-term futures price returns as it exhibits a volatility structure that decays exponentially as the time to maturity increases. In addition, this volatility specification implies that a shock will have the same directional impact on futures prices for all maturities, e.g. shortdated and long-dated futures prices will both increase or decrease. The volatility factor $\sigma_{2}\left(t, T, \mathbf{V}_{\mathbf{t}}\right)$ generates humps in the volatility structure, and thus it can capture the impact of the volatility of medium- to long-term futures prices. The long-end volatility factor $\sigma_{3}\left(t, T, \mathbf{V}_{\mathbf{t}}\right)$ increases as the time to maturity increases, thus it captures the volatility of medium- to long-term futures price returns. Note that for $\kappa_{3}<1$ this volatility factor can capture the empirically observed feature of shocks having opposite effect to the short-dated and long-dated prices, e.g. short-dated futures prices will decrease and long-dated futures prices will increase. The proposed volatility structure also allows each of the volatility factors to be driven by a different stochastic volatility processes, consequently our model has the potential to capture the impact of economic shocks to the entire term structure of the futures volatility (including short-, medium-, and long-term) and determine their contribution to the total variance.

While previous literature has highlighted the importance of using at least three volatility factors to adequately capture crude oil futures prices and their variation (see Chiang et al. (2015) and Cortazar et al. (2017)), these works are either limited to modelling only spot price volatility (Dempster et al. (2012), Cortazar et al. (2017), Gao et al. (2017), Christoffersen and Pan (2018)) or the volatility factors are not designed to capture the term structure of the futures price volatility. For instance, Trolle and Schwartz (2009) use three exponentially decaying factors, while Chiang et al. (2015) add a permanent shock factor to a transient and a growth trend factor. ${ }^{10}$ Chiarella et al. (2013) use general volatility factors and show that

\footnotetext{
${ }^{10}$ Dempster et al. (2012) use two exponentially decaying (with different rates of reversion) and one growth trend factor and show that short-term dynamics are driven by at least two factors, which is the case with our volatility specifications. Chiang et al. (2015) add a permanent shock factor (sensitive to technological shocks) to a factor that decreases with maturity (short-term or transient factor) and a factor that increases with maturity (long-term or growth trend factor). The fourth factor represents the unspanned volatility factor
} 
the typical factors in the crude oil futures volatility structure are exponentially decaying, hump-shaped, and increasing with maturity. Our modelling framework includes a shortend, a shape, and a long-end volatility factor. The short-end factor captures the short-term variations, while the shape and the long-end factor have the flexibility to model medium- to long-term variations and our empirical analysis disentangles/gauges these contributions.

\subsection{Futures and options prices}

It is well known that for general volatility specifications, the futures pricing model (3.1)(3.2) is Markovian in an infinite dimensional state space, but the volatility specifications (3.3) produce finite dimensional realisations of the model (Chiarella and Kwon (2001), Björk, Landén, and Svensson (2004)). Under the volatility specifications of $(3.3), \ln F\left(t, T, \mathbf{V}_{\mathbf{t}}\right)$ is affine in twelve state space variables, as described below:

$$
\ln F\left(t, T, \mathbf{V}_{\mathbf{t}}\right)=\ln F\left(0, T, V_{0}\right)+\sum_{n=1}^{5} \alpha_{n}(T-t) \xi_{n}(t)-\frac{1}{2} \sum_{m=1}^{7} \beta_{m}(T-t) \psi_{m}(t)
$$

The proposed model admits finite dimensional realisations within the affine class of Duffie and Kan (1996) and is, by construction, consistent with the currently observed futures price curve; consequently it is time-inhomogeneous. However for estimation purposes, it is necessary to reduce the model to a time-homogeneous representation as presented in Section 4.1. By employing Fourier transforms, call and put options on futures contracts can be priced in a quasi-analytical form. The technical details of the futures pricing equation (3.4) and the option pricing equations are available at the online Appendix (Appendix B). Furthermore,

that by definition does not explicitly relate to the futures prices, namely it is completely unspanned by futures prices. Generally, volatility risk is "partially" unspanned, see Trolle and Schwartz (2009) thus in our model, each volatility factor may be spanned by futures contracts at a different capacity. The assumption about the permanent shock factor infers that short-term futures prices and long-term futures prices will change by the same amount which is not typical in practice. Typically information shocks may increase the short-term futures prices more than the long-term futures prices or may increase the short-term futures prices and decrease the long-term futures prices and vice-versa, a feature that may well be captured by a hump-shaped term structure. The element missing from these specifications is that they do not easily identify shocks that will impact medium-term dynamics, such as the hump-shaped volatility term. We employ similar factors as in Chiang et al. (2015), but we add a hump-shaped one instead of the permanent shock factor. Cortazar et al. (2017) show that at least three factors are required to accurately fit the volatility surface of options. 
the market price of volatility risk is modelled with a "complete" affine specification (Doran and Ronn (2008), Dai and Singleton (2000)). More specifically,

$$
\begin{aligned}
& d \tilde{W}_{i}^{1}(t)=d W_{i}^{1}(t)+\lambda_{i}^{F} \sqrt{V_{t}^{i}} d t \\
& d \tilde{W}_{i}^{2}(t)=d W_{i}^{2}(t)+\lambda_{i}^{V} \sqrt{V_{t}^{i}} d t
\end{aligned}
$$

for $i=1,2,3$, where $\tilde{W}_{i}^{1}(t)$ and $\tilde{W}_{i}^{2}(t)$ are Wiener processes under the physical measure $P$.

\section{Model Estimation}

We estimate the parameters of the futures pricing model presented in Section 3 by using the extended Kalman filter and maximum likehood. The log-likehood function is computed using the built-in MATLAB global optimizer "Genetic Algorithm" routine for constrained optimization problems. ${ }^{11}$ The Riccatti ordinary differential equations of the characteristic functions are solved using MATLABs standard solver of ODE Runge-Kutta method of order 4 and 5 "ode45" with a variable time step for efficient computation. The integral for Fourier inversion of the characteristic function is computed using highly efficient numerical approximation, vectorized to enhance computational speed.

The model is fitted to 30 years of futures and option prices as described in Section 2. The price of the zero coupon bond $B\left(t, T_{o}\right)$ (discount function) used to price options is computed by fitting a Nelson and Siegel (1987) curve to LIBOR and swap data consisting of 1-, 3-, 6-, 9- and 12-month LIBOR rates and the 2-year swap rate (Trolle and Schwartz (2009), Chiarella et al. (2013)).

\footnotetext{
${ }^{11}$ The optimization involves searching for the minimal point of the negative of the log-likelihood function. The genetic algorithm is based on natural selection, which is a class of evolutionary algorithms and repeatedly modifies a population of individual solutions. The advantage of the global optimizer over the local optimizer is to avoid the solution being stuck in a local parameter space-domain. Since genetic algorithms do not produce the Hessian matrix necessary for the computation of the standard errors of the estimates, the estimated parameters are supplied into a local optimizer "fmincon" as initial parameters to obtain an estimate of the Hessian Matrix.
} 
Table 3: Parameter Estimates The table reports the quasi maximum-likelihood estimates of the commodity futures price model (standard errors are reported in parentheses) for the full sample period, January 1987-October 2017, and the two subsample periods, January 1987-December 2004, and January 2005October 2017. The time-homogenous futures price at time 0 is $F(0, t)=f_{0}, \sigma_{f}$ and $\sigma_{0}$ are the standard deviations of the log futures prices measurement errors and the option price measurement errors, respectively.

\begin{tabular}{|c|c|c|c|c|c|c|c|c|c|}
\hline & \multicolumn{3}{|c|}{ Jan 1987-Oct 2017} & \multicolumn{3}{|c|}{ Jan 1987-Dec 2004} & \multicolumn{3}{|c|}{ Jan 2005-Oct 2017} \\
\hline & $i=1$ & $i=2$ & $i=3$ & $\mathrm{i}=1$ & $i=2$ & $i=3$ & $i=1$ & $i=2$ & $i=3$ \\
\hline \multirow[t]{2}{*}{$\kappa_{i}$} & 0.53767 & 1.24930 & 3.00100 & 0.69378 & 0.47881 & 1.55829 & 0.46607 & 0.67685 & 0.58565 \\
\hline & $(0.0046)$ & $(0.0000)$ & $(0.0043)$ & $(0.0122)$ & $(0.0144)$ & $(0.01502)$ & $(0.0155)$ & $(0.0327)$ & $(0.0181)$ \\
\hline \multirow[t]{2}{*}{$\eta_{i}$} & 0.90905 & 0.38517 & 0.25100 & 0.79039 & 0.02868 & 1.51779 & 0.74268 & 0.76269 & 0.40887 \\
\hline & $(0.0034)$ & $(0.0107)$ & $(0.0026)$ & $(0.0000)$ & $(0.0134)$ & $(0.0144)$ & $(0.0054)$ & $(0.0139)$ & $(0.0141)$ \\
\hline \multirow[t]{2}{*}{$\mu_{i}$} & 0.74523 & 3.34262 & 2.07840 & 0.34521 & 0.07171 & 0.00416 & 0.16293 & 0.78949 & 0.18789 \\
\hline & $(0.0047)$ & $(0.0031)$ & $(0.0082)$ & $(0.0150)$ & $(0.0165)$ & $(0.0000)$ & $(0.0165)$ & $(0.0095)$ & $(0.0163)$ \\
\hline \multirow[t]{2}{*}{$\nu_{i}$} & 2.20528 & 0.00100 & 0.02891 & 0.56127 & 0.54652 & 0.46323 & 0.07995 & 0.65475 & 0.17399 \\
\hline & $(0.0032)$ & $(0.0028)$ & $(0.0077)$ & $(0.0149)$ & $(0.0141)$ & $(0.0000)$ & $(0.0156)$ & $(0.0156)$ & $(0.0166)$ \\
\hline \multirow[t]{2}{*}{$\varepsilon_{i}$} & 2.75249 & 4.83012 & 4.71474 & 0.76698 & 0.19203 & 0.91714 & 0.52750 & 0.79082 & 0.33730 \\
\hline & $(0.0031)$ & $(0.0000)$ & $(0.0040)$ & $(0.0092)$ & $(0.0145)$ & $(0.0000)$ & $(0.0000)$ & $(0.0000)$ & $(0.0166)$ \\
\hline \multirow[t]{2}{*}{$\rho_{i}$} & -0.20497 & -0.18664 & 0.21736 & -0.22638 & 0.60626 & -0.94654 & -0.10310 & -0.93169 & -0.02591 \\
\hline & $(0.0046)$ & $(0.0047)$ & $(0.0000)$ & $(0.0104)$ & $(0.0000)$ & $(0.0141)$ & $(0.0146)$ & $(0.0128)$ & $(0.0111)$ \\
\hline \multirow[t]{2}{*}{$\lambda_{i}^{F}$} & -0.14752 & 0.66719 & 0.17150 & 2.41498 & 0.27936 & 0.79249 & -1.98571 & -1.51575 & -1.87757 \\
\hline & $(0.0015)$ & $(0.0014)$ & $(0.0008)$ & $(0.0149)$ & $(0.0000)$ & $(0.0000)$ & $(0.0000)$ & $(0.0000)$ & $(0.0225)$ \\
\hline \multirow[t]{2}{*}{$\lambda_{i}^{V}$} & -2.48372 & -0.36788 & -1.41059 & -0.45070 & -0.27582 & 1.83443 & -1.2230 & -1.7886 & -2.98080 \\
\hline & $(0.0086)$ & $(0.0000)$ & $(0.0041)$ & $(0.0000)$ & $(0.0123)$ & $(0.0119)$ & $(0.0000)$ & $(0.0236)$ & $(0.0180)$ \\
\hline$f_{0}$ & & 1.4889 & & & 2.8946 & & & 2.0756 & \\
\hline$\sigma_{f}$ & & $3.16 \%$ & & & $1.50 \%$ & & & $1.95 \%$ & \\
\hline$\sigma_{0}$ & & $31.19 \%$ & & & $1.91 \%$ & & & $1.97 \%$ & \\
\hline
\end{tabular}

\subsection{Volatility Parameter Estimates}

Table 3 presents the quasi maximum-likelihood estimates of the model parameters over the full sample period, 1987-2017, and the two sub-sample periods, 1987-2004, and 20052017. ${ }^{12}$ Most of the volatility factors are persistent over the two sub-sample periods, which is evident from the relatively low values of $\mu_{i}$ that captures the degree of mean reversion. ${ }^{13}$ The correlation coefficients (between innovations in futures prices and volatility changes) are mostly negative and statistically significant. Over the full sample period, the estimates

\footnotetext{
${ }^{12}$ The crude oil futures market has experienced significant variation over the sample period thus the volatility factors have very different behaviour over the two sub-samples compared to the full sample. This is evident from the different estimates obtained over the three sample periods. Taking into consideration that the estimation methodology adjusts all parameter values to provide the best fit to observed market data, meaningful conclusions on the economic interpretations of these parameters can only be made if all parameter values are taken into account collectively. These individual estimates provide an indicative (but not conclusive) interpretation of each parameter estimate.

${ }^{13}$ Similar conclusions have been made from GARCH related literature; see Figuerola-Ferretti and Gilbert (2008) and Baum and Zerilli (2016).
} 
indicate that all three volatility factors are almost unhedgeable by futures contracts alone (correlations about 0.20). The estimates at the subperiods indicate that the longer term volatilities (shape and long-end factors) are more spanned by futures contracts than the short-end volatility factor. Furthermore, the signs of these correlations reveal changes in the return-volatility relation of crude oil futures prices: positive before and negative after 2004. This is possibly due to the financialisation of commodity markets raising the question as to what drives crude oil prices, commodity fundamentals, speculation and/or capital flows between markets (Kolodziej, Kaufmann, Kulatilaka, Bicchetti, and Maystre (2014), Chiarella, Kang, Nikitopoulos, and Tô (2016), Heath (2019), Baur and Dimpfl (2018)). The positive return-volatility relation is consistent to backwardation market conditions which was a typical pattern for the crude oil futures curve prior to 2008. However, since then the crude oil market has experienced extended periods of contango that has been attributed to impediments to inventory adjustments, inelastic oil supply and/or financial investing in commodity derivatives markets (Kilian (2016), Nikitopoulos et al. (2017)).

The estimates of the market price of crude oil futures price risk reveal a positive market price of risk before 2004 and a negative market price of risk after 2004. This result is consistent with Hamilton and Wu (2014). Also Li (2018) provides empirical evidence for this change in the risk premiums (from positive to negative) which is likely related to increased financialisation and speculative activity (compared to hedging) resulting in a lower level risk aversion for market participants. Financial speculators who seek portfolio diversification would take excess long crude oil futures positions requiring a smaller premium (especially when there is low hedging pressure). It is evident that following the financialisation of crude oil markets, the market price of crude oil futures prices is not only determined by commercial hedging but that speculative trading and investing seem to be also relevant. The estimates of the market price of volatility risk are negative which is consistent with results in an extensive literature explaining the customary empirical observations of higher implied volatilities compared to realised volatilities (Doran and Ronn (2008), Schwartz and 


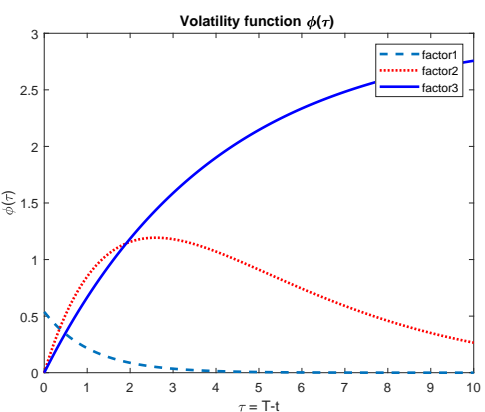

3.a

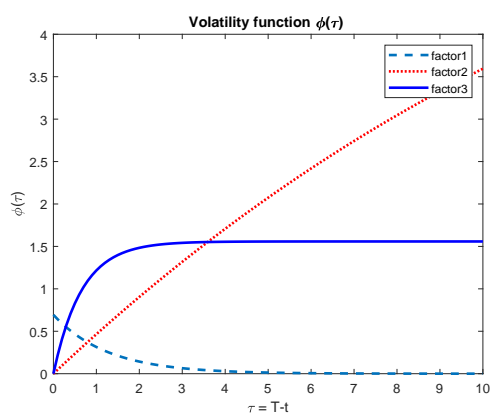

$3 . \mathrm{b}$

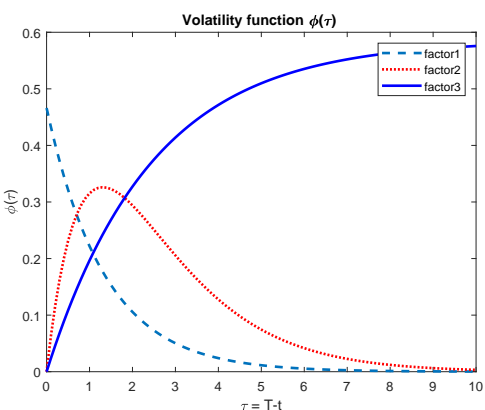

3.c

Figure 3: The shape of the three volatility factor loadings

The figure shows the volatility function $\phi_{i}(T-t)$, for $i=1,2,3$, of the futures pricing volatility processes for three periods; January 1987 to October 2017 in Figure 3.a, from January 1987 to December 2004 in Figure 3.b and from January 2005 to October 2017 in Figure 3.c.

Trolle (2010), Prokopczuk, Symeonidis, and Wese Simen (2017) and Hain, Uhrig-Homburg, and Unger (2018)).

Furthermore, the model fits well the futures and options data in the two sub-sample periods. As expected the model fit deteriorates over the full sample (with measurement errors being $3.16 \%$ to futures prices and $31.19 \%$ to option prices) due to the fact that the volatility displays very different characteristics (parameter values) over the two sub-sample periods and the liquidity of futures and options contracts have increased significantly over the years (see Section 2.1 for the liquidity-based data selection).

Figure 3 depicts the shapes of the three volatility factor loadings for different maturities which is the estimated deterministic part $\phi_{i}(t, T)$ of each latent volatility factor $\sigma_{i}$, namely $\sigma_{i}\left(t, T, \mathbf{V}_{\mathbf{t}}\right)=\phi_{i}(t, T) \sqrt{V_{t}^{i}}$ (see equation (3.3)). All three shapes of the volatility are present and significant ( $\kappa_{i}$ are statistically significant) with the exponential factor dying out in about two years, the shape term dominating medium terms from 1 to 3 years and the long-term factor having an effect after 1 to 2 years. In the 1987-2004 sample period, the shape type of volatility has a long term effect in the oil futures market as it only dies out at very distant maturities. The contribution of these factor loadings has to be assessed when combined with the volatility processes $V_{t}^{i}$, as we shall see in the next section. 


\subsection{The term structure of the futures price volatility}

In Figure 4, we depict the estimated time-series of volatilities $\sqrt{V_{t}^{i}}$ and $\sigma_{i}\left(t, T, \mathbf{V}_{\mathbf{t}}\right)=$ $\phi_{i}(t, T) \sqrt{V_{t}^{i}}$ for selected maturities (3 months, 12 months, 24 months and 48 months) and over the whole sample period from 1987-2017. Figure 5 and Figure 6 plot the estimated time-series of volatility variable $\sqrt{V_{t}^{i}}$ and $\sigma_{i}\left(t, T, \mathbf{V}_{\mathbf{t}}\right)$ over the two sub-sample periods, 19872004 and 2005-2017, respectively. The three volatility structures imposed by the model are the short-end volatility $\sqrt{V_{t}^{1}}$, the shape volatility $\sqrt{V_{t}^{2}}$ and the long-end volatility $\sqrt{V_{t}^{3}}$.

The short-end volatility factor $\sqrt{V_{t}^{1}}$ captures the main events that have affected crude oil prices over the years, while $\sqrt{V_{t}^{2}}$ and $\sqrt{V_{t}^{3}}$ also pick up some of these events. These include the Gulf War in 1991, the Asian financial crisis aftermath in 1998, the OPEC decision to cut oil output by 1.5 million barrels in 2001, the US invasion to Iraq in 2003, the Global Financial Crisis in 2008, the Arab spring in 2011, the oil crash in 2014, and the recent crude oil glut between 2014-2016. These events can be observed at the top panel of Figure 4. As expected, as time to maturity increases, the short-end volatility term $\sigma_{1}\left(t, T, \mathbf{V}_{\mathbf{t}}\right)$ decreases, while both the shape volatility term $\sigma_{2}\left(t, T, \mathbf{V}_{\mathbf{t}}\right)$ and the long-end volatility term $\sigma_{3}\left(t, T, \mathbf{V}_{\mathbf{t}}\right)$ increase.

Table 4 presents the contributions of each volatility factor to the total variance. For the very short maturity contracts (up to three months) almost all of the variance is related to the short-term variations; $93.40 \%$ in the full sample and $94.15 \%$ to $97.20 \%$ in the two sub-sample periods, respectively. The short-term variations also dominate the variance of contracts with maturities between three and six months but the contributions are reduced to $75.40 \%$ and $84.52 \%$, in the two sub-sample periods, respectively. For contracts with maturities of 6 months to 12 months, $56 \%$ to $65 \%$ of the variance is attributed to short-term variations, while for maturities above 24 months, typically one of the other two factors dominates (either the shape or the long-end). The information presented in Table 4 identifies the dominating volatility factors in the term structure of the futures price volatility, especially for medium- to long-term maturities. The dominating volatility factor in the medium-term crude oil futures 
Table 4: Contribution of crude oil volatility factors

The table reports the contribution of each volatility factor to the total variance. The three volatility factors include the short-end volatility $\sqrt{V_{t}^{1}}$ (short-end), the shape volatility $\sqrt{V_{t}^{2}}$ (shape) and the long-end volatility $\sqrt{V_{t}^{3}}$ (long-end). $\sqrt{V_{t}^{1}}, \sqrt{V_{t}^{2}}$ and $\sqrt{V_{t}^{3}}$ are the corresponding stochastic volatility drivers of the volatility terms $\sigma_{1}, \sigma_{2}$ and $\sigma_{3}$, respectively (see equations 3.3).

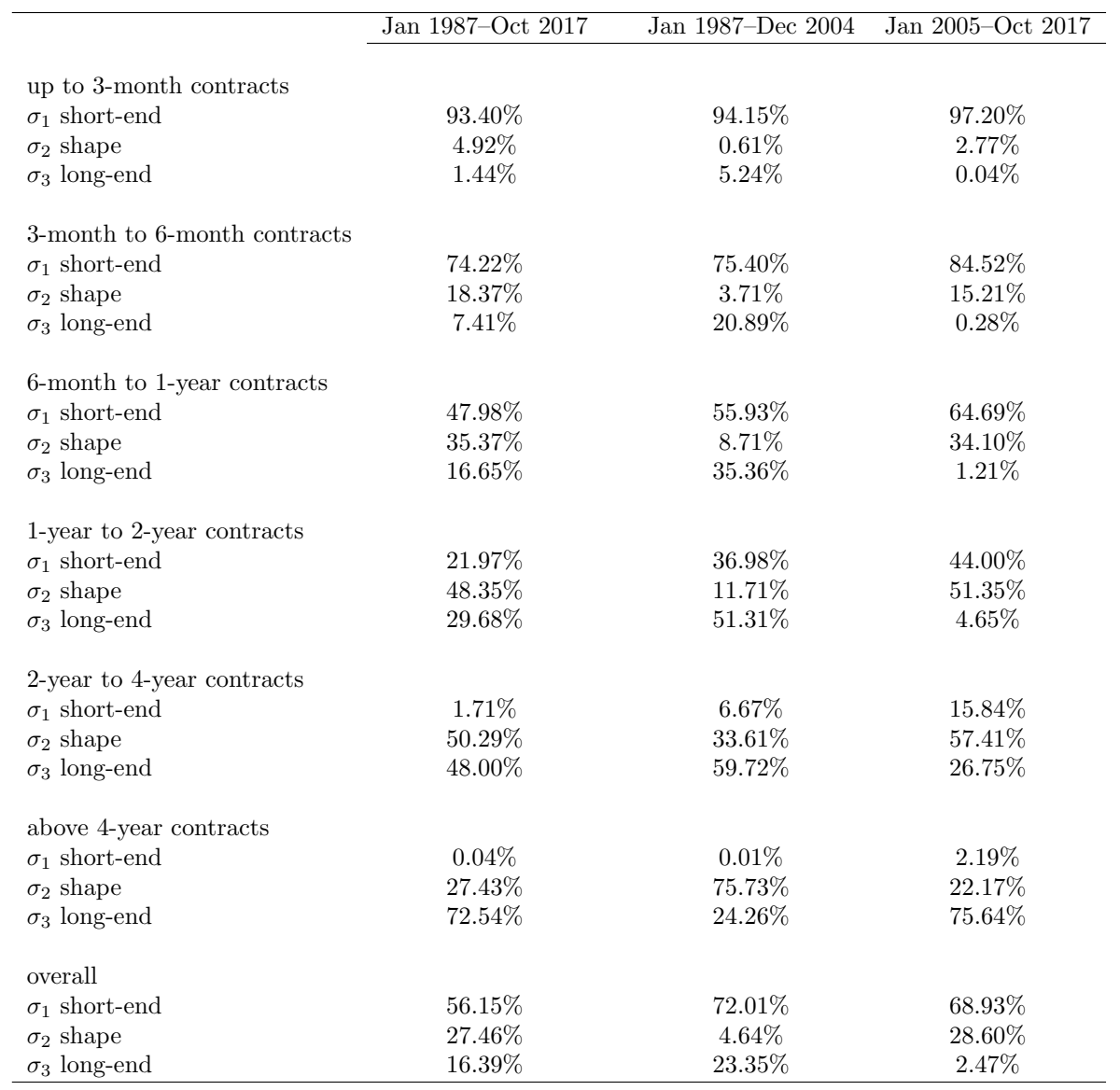

contracts (between 1 to 4 years) in the 1987-2004 period is the long-end factor $\sqrt{V_{t}^{3}}$, while in the 2005-2017 period the shape factor $\sqrt{V_{t}^{2}}$ dominates. Indeed, before $2004,51.31 \%-59.72 \%$ of the variance is attributed to the long-end factor, while after $2004,51.35 \%-57.41 \%$ of the variance is attributed to the shape factor. Thus we categorise as "medium-term" futures price volatility, the long-end factor $\sqrt{V_{t}^{3}}$ in the sample period 1987-2004 and the shape factor $\sqrt{V_{t}^{2}}$ in the sample period 2005-2017. This is a result of the flexibility of the shape volatility factor. ${ }^{14}$ For the long-term crude oil futures contracts, e.g. more than 4 years, the

\footnotetext{
${ }^{14}$ If the hump appears within one to two years then the shape volatility factor captures medium-term variations. However, if the hump moves to longer maturities then this volatility factor would capture longterm variations as it is increasing with maturity for reasonably long periods of time.
} 
dominating volatility factor is the shape factor $\sqrt{V_{t}^{2}}$ (with contribution of $75.73 \%$ ) in the 1987-2004 period, and the long-end factor $\sqrt{V_{t}^{3}}$ (with contribution of 75.64\%) in the 20052017 period. Figure 3 depicts the shapes of the estimated volatility factor loadings and shows that in 1987-2004, the shape volatility factor $\sqrt{V_{t}^{2}}$ does not have a hump within the time frame. Thus it displays an increasing with maturity volatility structure and consequently it contributes to the long-term futures price volatility (Chiarella et al. (2013)), which draws the same conclusions as the ones suggested from Table 4. Accordingly, we categorise as "long-term" futures price volatility, $\sqrt{V_{t}^{2}}$ in the sample period 1987-2004 and $\sqrt{V_{t}^{3}}$ in the sample period 2005-2017.

Hitzemann (2016) provides empirical evidence that for contracts up to 6 months $70 \%$ of the variability relates to oil productivity shocks while for contracts up to 12 months only $50 \%$ of the variability relates to oil productivity shocks with the remaining contributions to the variance coming from short-run and long-run macro factors. Kilian (2009) argues that a large proportion of oil price changes are related to oil-specific shocks. To identify the determinants of the crude oil futures price volatility, in the next section we will investigate the relationship between each of these estimated volatility factors and economic variables such as oil sector variables and financial variables.

\section{Economic determinants of the volatility term structure}

In this section, we identify the economic determinants of the three volatility factors, i.e. the economic drivers that characterize the term structure of the oil futures price volatility by regressing the volatility factors on respective economic variables. To control for the volatility persistency, we include one lag of the volatility factor. Note that the volatility factors are orthogonal by construction, so there is no need to include the other factors. By modelling the entire term structure of the crude oil futures volatility, these relationships are analysed for different maturity horizons. The economic variables used in the empirical study can be categorised into three types. Firstly, oil sector variables including the de-trended logarithm of 
inventory $(\operatorname{Inv})$, the first differences in logarithm of consumption $(D(C o n s))$, the 12-month futures spread (FutSpread Fim $_{12}$ ), the logarithm of open interest $(O I)$ and hedging pressure $(H P)$. Secondly, the macro-economic conditions/business cycle variables include the first differences in Treasury yield spreads $(D(T S))$, the de-trended consumer price index $(C P I)$, the Chicago Fed National Activity Index $(C F N A I)$ and de-trended Industrial Production $(I P)$. Lastly, the financial variables consist of the S\&P 500 index (S\&P500), the VIX (VIX), the Fama-French SMB factor (FFsize), the Fama-French HML factor (FFvalue), Momentum(Mom), 3-month Treasury rates $\left(T R_{3 m}\right)$, the first differences in the US dollar index $(D(U S D I))$, and credit spreads $(C S)$ (see Section 2.2 for details). Table 5, Table 6, and Table 7 present the regression coefficients of regressions of these economic variables and the volatility factors $\sqrt{V_{t}^{1}}, \sqrt{V_{t}^{2}}$ and $\sqrt{V_{t}^{3}}$, respectively, during the 1987-2004 period. Table 8, Table 9 and Table 10 display the corresponding results in the 2005-2017 period. All three volatility factors are highly persistent as expected.

\subsection{Short-term futures price volatility}

The short-end volatility $\sqrt{V_{t}^{1}}$ relates consistently to hedging pressure and VIX over both subperiods, see Table 5 and Table 8 . Hedging pressure (representing the net positions of hedgers in futures markets) plays an important role for short-term volatility, a relation that holds before and after financialisation. Motivated by Keynes (1930) and Hicks (1939), de Roon, Nijman, and Veld (2000) identify the significance of hedging pressure in several futures markets in explaining futures returns with a dataset up to 1994. Basu and Miffre (2013) use a variety of commodity futures markets to demonstrate that hedging pressure determines commodity futures risk premia. Our findings complement these results by documenting the enduring importance of hedging pressure in determining not only returns but additionally the short-term volatility of crude oil futures prices.

It is well documented that co-movements and volatility spillovers between commodity and equity markets exist and have strengthened as a result of financialisation (Kilian and Park (2009), Arouri, Jouini, and Nguyen (2011), Tang and Xiong (2012)). VIX is positively 
related to commodity index return volatilities (Basak and Pavlova (2016)), a result that is supported by our findings, yet we do not find significant differences in terms of this relation between the two sub-periods. Further, VIX has significant explanatory power for short-dated oil option-implied volatilities, as demonstrated in Robe and Wallen (2016).

Nevertheless, there are significant differences between the determinants of short-term volatility across the two sub-periods, which are evident by comparing Table 5 and Table 8 . Commodity spot volatility is generally not predicted by inventories or convenience yields, consistent with the exogeneity property of volatility implied from information efficiency between spot and futures markets (Pindyck (2004)). However, after 2004, $\sqrt{V_{t}^{1}}$ exhibits a positive relation with the 12-month futures spread. Nikitopoulos et al. (2017) demonstrate that lags of volatilities, in particular implied volatilities, are significant predictors of futures spreads of longer maturities (e.g. 12-month futures spreads). Further the positive futures spreads which indicate contango market conditions (the crude oil market has experienced extended periods of contango since 2004), relate to shocks in volatility as predicted by Kogan, Livdan, and Yaron (2009).

The impact of macro-economic and financial conditions on short-term futures price volatility changes significantly across the two sub-periods, which might be due to financialisation. Prior to 2004, short-term volatility is related to FF size (along with the VIX), enforcing the notion that crude oil prices and their volatilities were mostly driven by commodity markets fundamentals (Fan and Xu (2011)). However, after 2004, the short-term volatility is related to key variables of macro-economic and financial conditions, including industrial production, CFNAI, the S\&P 500 returns, the term spread, the US dollar index, and the credit spread. Recent literature including Mollick and Assefa (2013) and Heath (2019) provide evidence of the strong relationship between oil futures prices and economic activity (measured by industrial production and CFNAI). We provide evidence that this relation also holds for volatility.

The term spread is commonly considered as measure of the expected direction of the 
near-term monetary policy, with an inverted Treasury term structure providing a strong indication for an upcoming recession (Estrella and Hardouvelis (1991) Estrella and Mishkin (1998), Wheelock and Wohar (2009) and Bauer and Mertens (2018)). ${ }^{15}$ Accordingly, after 2004, the lower term spreads observed over the recent history are associated to higher shortterm volatility. Measures of financial uncertainty and default risk serve as key predictors of commodity futures price volatility (as supported also by Hitzemann (2016), Gao et al. (2017) and Prokopczuk et al. (2019)), while index returns and exchange rates are associated with futures price volatility via capital flows within markets (Tang and Xiong (2012), Heath (2019)). The bidirectional causality between the US dollar and oil prices reported after financialisation by Schneider, Van Robays, and Fratzscher (2014) provides some grounds for the strong relation between short-term oil volatility and the changes in the US dollar index since 2004 .

\subsection{Medium-term futures price volatility}

In Section 4.2 the contribution of each estimated volatility factor to the total variance is assessed and we find that the volatility factor that dominates in the medium-term (between 1 to 4 years) is captured by the latent volatility term $\sqrt{V_{t}^{3}}$ in 1987-2004 and the latent volatility term $\sqrt{V_{t}^{2}}$ in 2005-2017, which is the characterisation we use in the following sections.

Crude oil inventories typically are related to historical spot price volatility, see Geman and Ohana (2009) and Nikitopoulos et al. (2017). From Table 7, it is evident that the medium-term volatility $\sqrt{V_{t}^{3}}$ in 1987-2004 is also related to the inventories, a relation that is weaker and with opposite sign compared to that identified after 2004 (a negative sign opposed to a positive sign after 2004). According to the theory of storage, low inventory induces high volatility ( $\mathrm{Ng}$ and Pirrong (1994)). Yet we find that after 2004, the medium-

\footnotetext{
${ }^{15} \overline{\text { Recent concerns on the statistical power of these predictors due to the current low levels of term spreads }}$ have motivated literature on alternative predictors such as near-term forward spreads (Engstrom and Sharpe (2018) and Fendel, Mai, and Mohr (2019)).
} 
term volatility $\sqrt{V_{t}^{2}}$ holds a positive relation with inventories (see Table 9 ). The extended periods of contango experienced by the oil futures markets (amid the recent restrictions in the crude oil refining and distribution industry due to the expansion of the shale oil market and the crude oil export ban) may have played a role in making this relation stronger and positive in the second sub-sample (Kilian (2016)).

Further, it has been found that since 2004, consumption impacts implied volatility of longer maturity futures contracts (Nikitopoulos et al. (2017)), which is consistent with identifying a relation between the medium term futures volatility $\sqrt{V_{t}^{2}}$ and crude oil consumption. Despite following a positive time trend over the years, crude oil consumption has experienced a negative trend since 2000, as a result of slower economic growth and improvements on fuel usage (CEA (2015)), which is also reflected gradually in the volatility. Kilian and Murphy (2014) provide evidence that "oil consumption driven by the global business cycle" has contributed to the oil price surge in 2008. Even though business cycle variables do not directly and strongly affect the medium term volatility, the impact of these macro-economic conditions have been transmitted to the medium-term volatility via precautionary demand shocks and inventory adjustments. Oil sector variables such as oil inventory and consumption tend to impact the medium-term volatility, a result that contradicts earlier evidence documented by Pindyck (2004) of a non-existing relation between futures price volatilities and oil sector variables. Moreover, trading variables exhibit strong negative relationships with short-term to medium-term volatility. While hedging pressure relates to short-term volatility, open interest impacts the medium-term volatility with the effect becoming stronger after 2004 .

Macro-economic and financial variables such as the consumer price index, industrial production, VIX, and the credit spreads tend to impact the medium-term volatility to some extend (in both sub-periods). As discussed above, these variables have played an important role in determining the short-term future price volatility after 2004, but these are also key drivers of the medium-term futures price volatility. Chiang et al. (2015) find that their "persistent" risk factor is strongly related to VIX and inflation, which is also evident in the 
considerable impact these two economic variables have on the short-term and medium-term volatility factors. Prokopczuk et al. (2019) and Heath (2019) find a two-way relation between oil prices and real activity (one channeled via industrial production and the other via consumer spending). Further, the important role of oil prices in determining inflation (Chen, Turnovsky, and Zivot (2014)) justifies the suitability of oil futures as hedging instruments of inflation risk, which may tide oil futures markets and their volatility closer to inflation variations (Szymanowska, De Roon, Nijman, and Van den Goorbergh (2014) and Heath (2019)). After 2004, indicators of economic recessions, as measured by the Treasury bond yield spreads, tend to also relate to medium-term volatility.

\subsection{Long-term futures price volatility}

According to Table 4, the long-term futures price volatility is captured by $\sqrt{V_{t}^{2}}$ in the sample period 1987-2004 and by $\sqrt{V_{t}^{3}}$ in the sample period 2005-2017, as these volatility factors dominate the volatility of futures contracts with maturities of 4 years and above.

Before 2004, the long-term volatility factor $\sqrt{V_{t}^{2}}$ is mostly driven by the open interest, the bond yield spreads, the 3-month Treasury rates, and the credit spreads, while in the latter sub-period, it is only the 3-month Treasury rate that matters in the long term. Our results identify a positive relation between the long-term futures price volatility and interest rates (represented by the 3-month Treasury rates) in the early sample period that reverses after 2004 (see Table 6 and Table 10).

Typically, interest rates increase the cost of holding inventory, which is reflected in higher convenience yields and in turn these changes in convenience yields can then be transmitted in the futures price volatility (Casassus and Collin-Dufresne (2005)). As in the early sample period, oil specific shocks matter more to the oil futures volatility compared to shocks from macro-economy. This could provide a channel to transmit positive shocks in interest rates to higher oil futures volatility. However, it is empirically documented that in more recent years, oil prices and oil futures prices are negatively correlated with short-term real interest rates (Arora and Tanner (2013), Cheng et al. (2018)). Since 2009, the majority of the 
world's advanced economies have experienced a low-interest-rate environment attributed to slow global economic growth and an increased premium for holding liquid and safe assets (Del Negro, Giannone, Giannoni, and Tambalotti (2018)). On the other hand, over the same period, oil futures volatility has considerably increased as a result of the financialisation and structural changes in the oil markets.

\subsection{Determinants of the oil futures price volatility}

To provide an overall evaluation of the key determinants of the term structure of the oil futures volatility, it is important to consider the contributions of each of these three volatility factors to the total variance (reported in Table 4). This table reveals that, after 2004 the contribution of the short-end volatility term to the total variance of short term futures prices reaches $64.69 \%$ for up to one-year futures contracts and $44.00 \%$ for up to two-year futures contracts, compared to $55.93 \%$ and $36.98 \%$ respectively, prior to 2004 . This suggests that after 2004, macro-economic and financial conditions such as industrial production, credit spreads, and the US dollar index have played a dominant role in determining the volatility of oil futures contracts for maturities of up to 1 year. At the same time, hedging pressure and the VIX have been closely related to short-term futures price volatility over the years, and indeed these have always been the two key drivers of short-term volatility. Thus we conclude that, since 2004, the volatility of short-dated oil futures contracts is related not only to hedging pressure and the VIX but also to futures spreads. Most importantly, effects from financial and macro-economic conditions have a significant impact on the short-term oil price variations, which may be attributed to the financialisation of the commodities markets.

The contribution of the medium-term volatility factor to the total variance is very similar between the two sub periods; $34.10 \%-35.36 \%$ of the total variance of up to one-year crude oil futures contracts and $51.31 \%-51.35 \%$ of the volatility of up to two-year futures contracts, reaching almost $60 \%$ for maturities up to four years. This volatility is driven by oil specific variables such as inventory, consumption and open interest especially in the later sub-sample, while consumption price index, industrial production, VIX and credit spreads have a lesser 
but lasting impact on the medium-term futures price volatility. We identify that, for futures contracts with middle range maturities, inflation and financial variables such as VIX and credit spreads matter the most. However, since 2004, oil-specific factors including inventory, consumption and open interest have an equally important role in explaining the volatility.

Table 4 reports that the long-term futures price volatility contributes less than $12 \%$ of the total variance to contracts with maturity less than two years, about a quarter to one third of the variance of contracts up to four years, while it dominates the variance of futures contracts above four years $(75.73 \%-75.64 \%)$. Consequently we conclude that for futures contracts with very long maturities, the interest rates comprise the key determinant of their volatilities with a marginal impact from macro-economic variables such as credit spreads and bond yield spreads.

\section{Robustness Tests}

Additional investigations are conducted as robustness tests. We firstly compare the results with the relationships between the economic variables and the estimated volatilities when we fit the model over the whole sample period of thirty years. The results of the whole sample have been added to amplify three points: a) the significant changes in crude oil futures markets which cannot be captured by fitting only to the whole sample, b) to identify the economic determinants that consistently impact the term structure of the crude oil volatility independent of the changes in the market conditions, and c) the importance of assessing the volatility dynamics in two sub-sample periods as it detects economic factors which are subject to the changing conditions in the crude oil futures markets. We also run the analysis with weekly frequency (but with less explanatory variables due to data availability). ${ }^{16}$

\footnotetext{
${ }^{16}$ Further we also consider the variance instead of the volatility factors for the full analysis and we found similar results. These are available upon request.
} 


\subsection{Full Sample}

The regression results over the whole sample period of 30 years, from 1987 to 2017 are available on the online Appendix (Appendix C). VIX, credit spread, FFsize and hedging pressure (in the order of significance) are the main determinants of the short-term futures price volatility. Thus, VIX and hedging pressure hold significant relationships with the short-term structure of the futures price volatility, at all sample periods considered in our analysis. FFsize is significant in the first sub-sample period (Table 5), while the credit spreads (together with other economic variables) dominate after 2004 (Table 8).

From Table 4 we deduct that, the medium-term volatility is represented by $\sqrt{V_{t}^{2}}$, while the long-term volatility is captured by $\sqrt{V_{t}^{3}} \cdot{ }^{17}$ Open interest, the 3-month Treasury rate, CFNAI, and industrial production contribute to the overall medium-term futures price volatility. From Table 7 and Table 9, it is evident that open interest is consistently one of the main determinants of medium-term volatility with stronger dependence after 2004, while in the sub-sample periods, the 3-month Treasury rate seems to relate more to the long-term volatility factor. The macro-economic conditions of CFNAI and industrial production also play an important role in the overall medium-term volatility. In the first sub-sample, the mediumterm volatility is influenced by industrial production and consumer price index, while after 2004, macro-economic conditions such as industrial production and CFNAI impact the shortterm volatility. The long-term volatility is generally affected by the open interest, Mom and inventory (in the order of significance), a relation that also holds in the sub-sample periods but only for the open interest. Inventory is one of the determinants of the medium-term volatility in both sub-samples. The overall results on the main determinants of the volatility term structure are robust in terms of the sample period. We identify VIX and hedging pressure as the key determinants of the volatility of short-term futures contracts, while open interest, 3-month Treasury rates, and industrial production are the key determinants of the

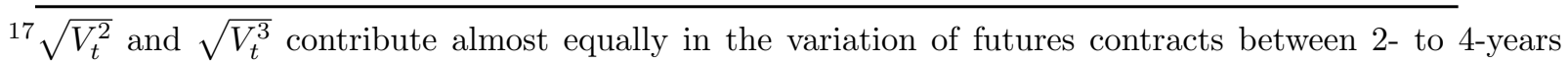
while $\sqrt{V_{t}^{3}}$ dominates the variation for contracts above 4 years.
} 
volatility of medium-term futures contracts.

\subsection{Weekly frequency}

The analysis with weekly data includes only 12 explanatory variables due to data availability. ${ }^{18}$ We find that hedging pressure and VIX remain the two key determinants of crude oil short-term volatility in both sub-sample periods and across the entire sample. In the medium-term volatility, open interest is consistently more important than the hedging pressure, with interest rates affecting this volatility before 2004 and FF size after 2004. Finally, the crude oil long-term futures price volatility is consistently associated with open interest and interest rates, while the bond yields and FF value become important for long-term volatility after 2004. Again, the overall results are consistent with the findings over the two sub-periods. Unfortunately due to the lack of weekly data for credit spreads, consumption, consumer price index, and industrial production we cannot investigate the impact of these economic factors on the volatility. For the sake of brevity, the results using the weekly data are available upon request.

\section{Conclusion}

The importance of oil derivatives markets in risk management and trading practices has again become apparent from the turmoil that the oil markets have witnessed over the years and has led to substantial volatility in this market. This has motivated us to conduct a comprehensive study on the determinants of the crude oil futures price volatility. First, we develop a general stochastic volatility model for the term structure of commodity futures. Using our model and data from crude oil derivatives, we estimate the associated volatility factors and then identify their determinants by studying the links between the futures price volatility structure and the macro-economy as well as oil-specific variables.

\footnotetext{
${ }_{18}^{18}$ The explanatory variables used are Inv, FutSpread ${ }_{12 m}, O I, H P, D(T S)$, FFsize, FFvalue, Mom, $S \& P 500, V I X, T R_{3 m}$ and $D(U S D I)$.
} 
This paper proposes a tractable and consistent stochastic volatility futures pricing model well suited to portray three distinct volatility factors capturing short-term, medium-term and long-term variations of oil futures prices. The term structure of the futures price volatility is estimated by using 30 years of crude oil derivative prices (split in 2004). All volatility factors are highly persistent and unspanned. New evidence emerges showing that short-end volatility factors are less spanned by futures contracts compared to the longer maturity volatility factors. Since 2004, the correlation coefficients between innovations in futures prices and the shape volatility, and the market price of futures price risk for all three volatility factors have changed from positive to negative, proving evidence of a higher level of integration between oil markets and financial markets in recent years.

An examination of the determinants of the term structure of the crude oil futures price volatility reveals significant changes in the economic drivers of short-term and medium-term volatility factors over time. Since 2004, the short-term volatility is more responsive not only to conventional hedging pressure and VIX but also to the futures spreads and to macroeconomic conditions and financials such as industrial production, credit spreads, and the US dollar index. The medium-term volatility factor is generally related to macro-economic conditions and financial variables such as the consumption price index, industrial production, VIX, and the credit spreads, but since 2004, oil specific variables such as inventory, consumption, and open interest have also become key determinants. Long-term volatility is mainly driven by interest rates with a marginal effect from the credit and bond yield spreads.

Our findings have important implications. Oil futures volatility is the result of the complex interactions of factors in both the oil sector and the macro-economy. Consequently managing the risks associated with this volatility requires a blend of prudent considerations and mutually consistent policies. The strong connection between inflation and oil futures volatility must be carefully considered when commodity importing countries decide on any monetary tightening. The considerable impact that the hedging pressure and open interest has on short-term and medium-term futures price volatility stresses the importance of 
market transparency and effective strategies to smooth out extreme volatilities potentially caused by excessive trading of institutional investors. The immediate impact of VIX and credit spreads, against the slower responsive impact of inventory and consumption on the oil futures volatility requires special attention from oil-producing countries as well as institutional investors. This paper provides a tractable framework to quantify this volatility, and consequently to disentangle the factors driving it. It offers useful insights to financial modellers, commodity market participants and policy makers to better understand the volatility of crude oil futures markets and its determinants and, thus be able to more efficiently use and manage it.

\section{Acknowledgements}

We thank the editor Richard S.J. Tol, two anonymous reviewers, the late Carl Chiarella, Susan Thorp, Erik Schlögl, Yubo Tao (discussant), and Isabel Figuerola-Ferretti (discussant) for useful comments at various stages of this research. We also thank seminar participants at the 2019 Sydney Financial Mathematics Workshops (Sydney), the Commodity and Energy Markets Conference 2019 (Pittsburgh), the 3rd Australasian Commodity Markets 2019 conference (Sydney) and the UTS Finance Department internal research seminars and showcase events for fruitful discussions and suggestions. Special thanks go to Mesias Alfeus and Ni-

had Aliyev for assisting with data management and numerics. Australian Research Council financial support (DP 130103315) is gratefully acknowledged. The usual disclaimer applies.

\section{Appendix. Supplementary data}

Supplementary data to this article can be found online at ADD LINK HERE. 

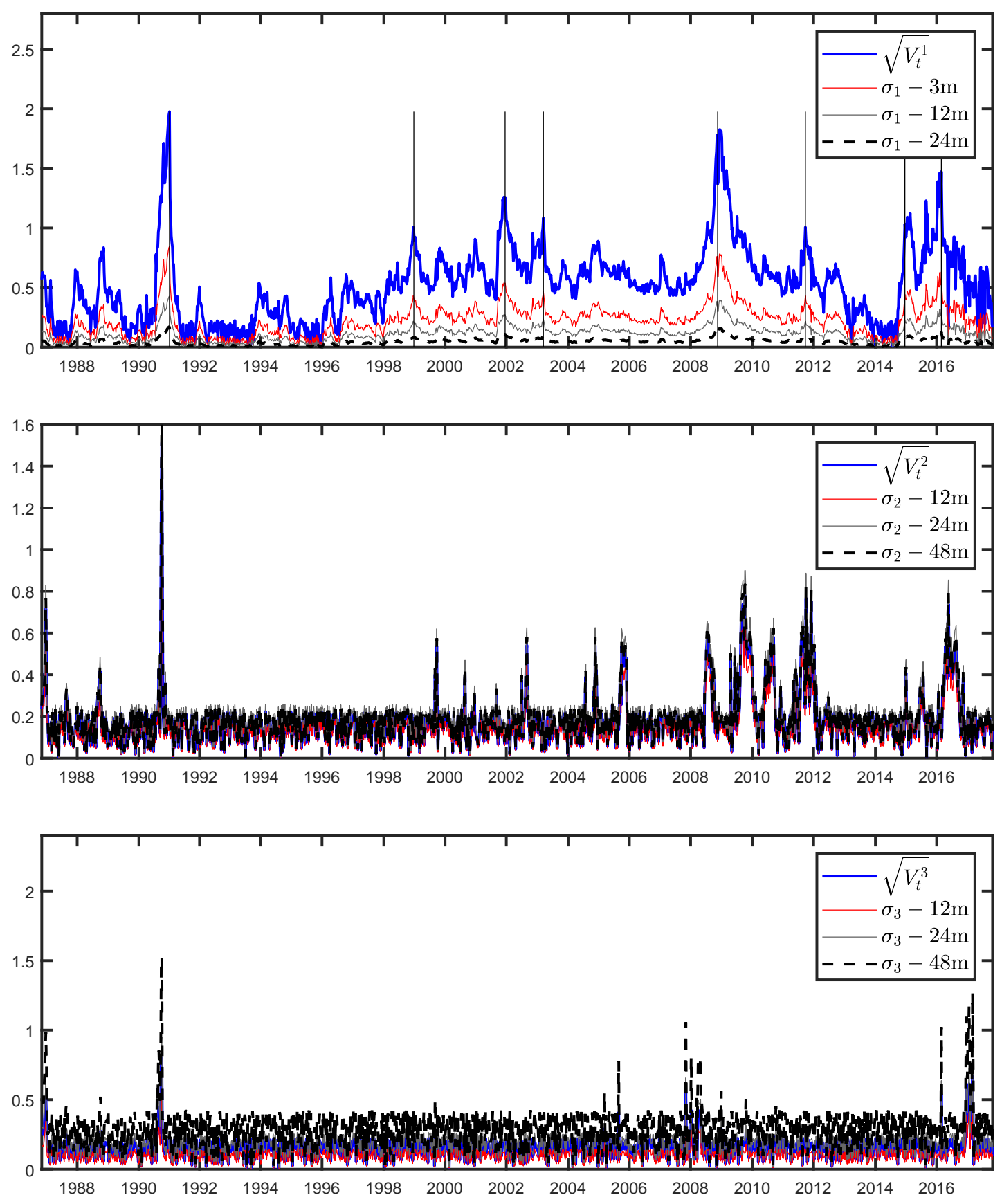

Figure 4: Crude oil volatility factors $\sqrt{V_{t}^{i}}$ and $\sigma_{i}\left(t, T, \mathbf{V}_{\mathbf{t}}\right)-\mathbf{1 9 8 7 - 2 0 1 7}$

The figure displays the estimated time-series of the crude oil volatility factors $\sqrt{V_{t}^{i}}$ and $\sigma_{i}\left(t, T, \mathbf{V}_{\mathbf{t}}\right)=$ $\phi_{i}(t, T) \sqrt{V_{t}^{i}}$, for $i=1,2,3$, over the period from 1987 to 2017. $\sigma_{1}$ is displayed for three maturities; 3 months, 12 months and 24 months, while $\sigma_{2}$ and $\sigma_{3}$ are displayed for 12 months, 24 months, and 48 months. The top panel plots the volatility variables for the first volatility term, the middle panel for the second volatility term, and bottom panel for the third volatility term. 

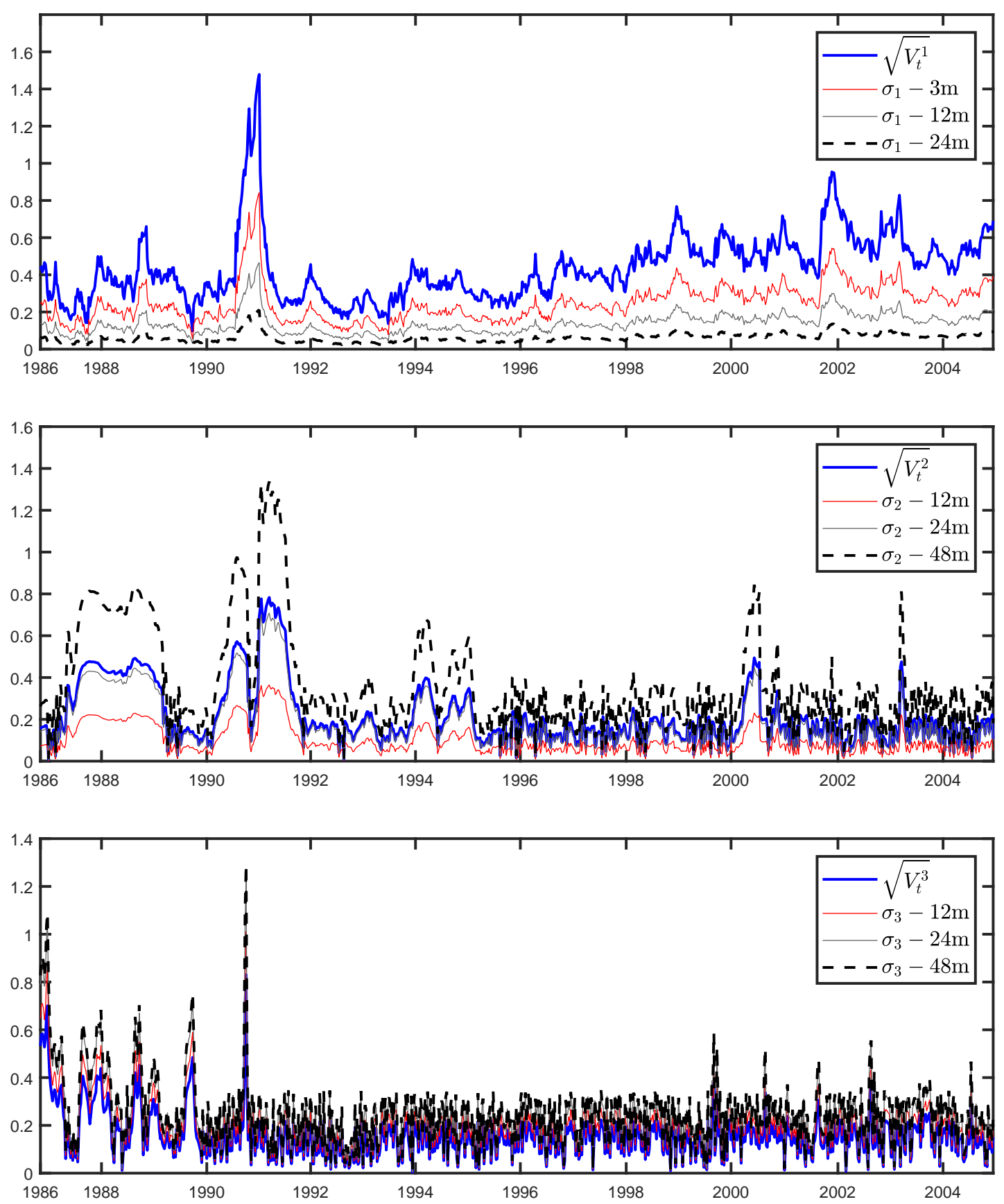

Figure 5: Crude oil volatility factors $\sqrt{V_{t}^{i}}$ and $\sigma_{i}\left(t, T, \mathbf{V}_{\mathbf{t}}\right)-\mathbf{1 9 8 7 - 2 0 0 4}$

The figure displays the estimated time-series of the crude oil volatility factors $\sqrt{V_{t}^{i}}$ and $\sigma_{i}\left(t, T, \mathbf{V}_{\mathbf{t}}\right)=$ $\phi_{i}(t, T) \sqrt{V_{t}^{i}}$, for $i=1,2,3$, over the period from 1987 to 2004 . $\sigma_{1}$ is displayed for three maturities; 3 months, 12 months and 24 months, while $\sigma_{2}$ and $\sigma_{3}$ are displayed for the 12 months, 24 months, and 48 months. The top panel plots the volatility variables for the first volatility term, the middle panel for the second volatility term and bottom panel for the third volatility term. 

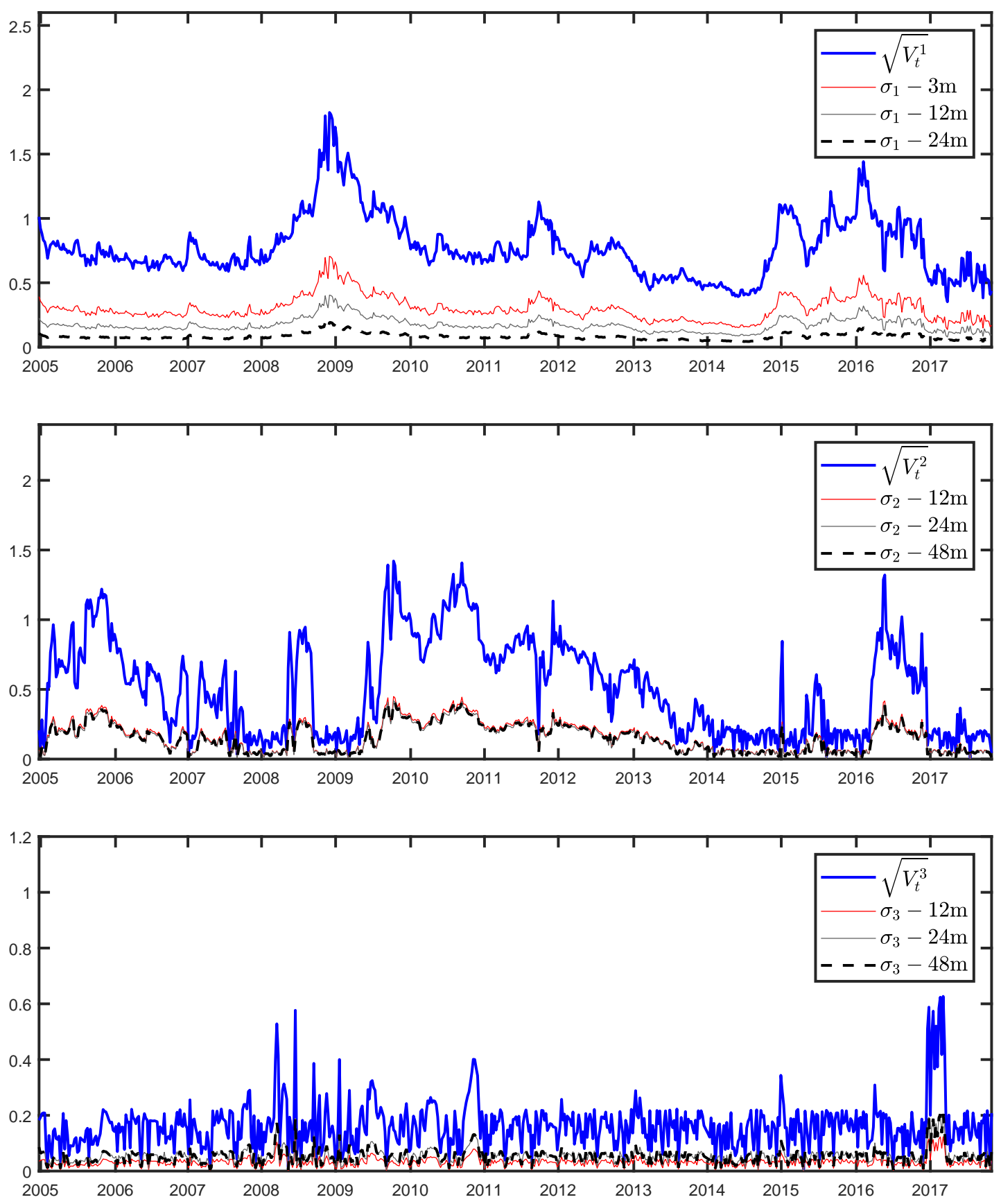

Figure 6: Crude oil volatility factors $\sqrt{V_{t}^{i}}$ and $\sigma_{i}\left(t, T, \mathbf{V}_{\mathbf{t}}\right)-\mathbf{2 0 0 5 - 2 0 1 7}$

The figure displays the estimated time-series of the crude oil volatility factors $\sqrt{V_{t}^{i}}$ and $\sigma_{i}\left(t, T, \mathbf{V}_{\mathbf{t}}\right)=$ $\phi_{i}(t, T) \sqrt{V_{t}^{i}}$, for $i=1,2,3$, over the period from 2005 to 2017. $\sigma_{1}$ is displayed for three maturities; 3 months, 12 months and 24 months, while $\sigma_{2}$ and $\sigma_{3}$ are displayed for the 12 months, 24 months and 48 months. The top panel plots the volatility variables for the first volatility term, the middle panel for the second volatility term and bottom panel for the third volatility term. 


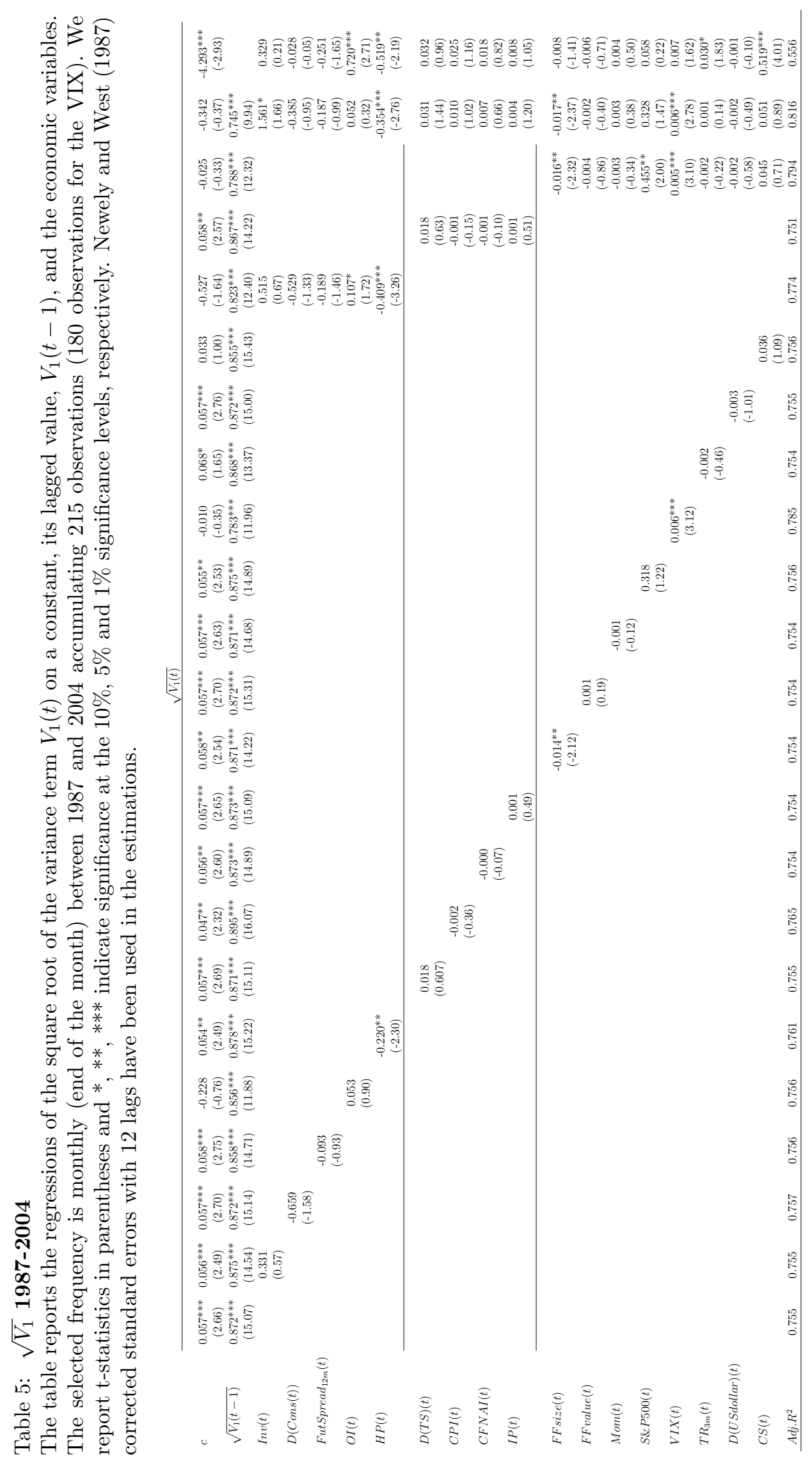




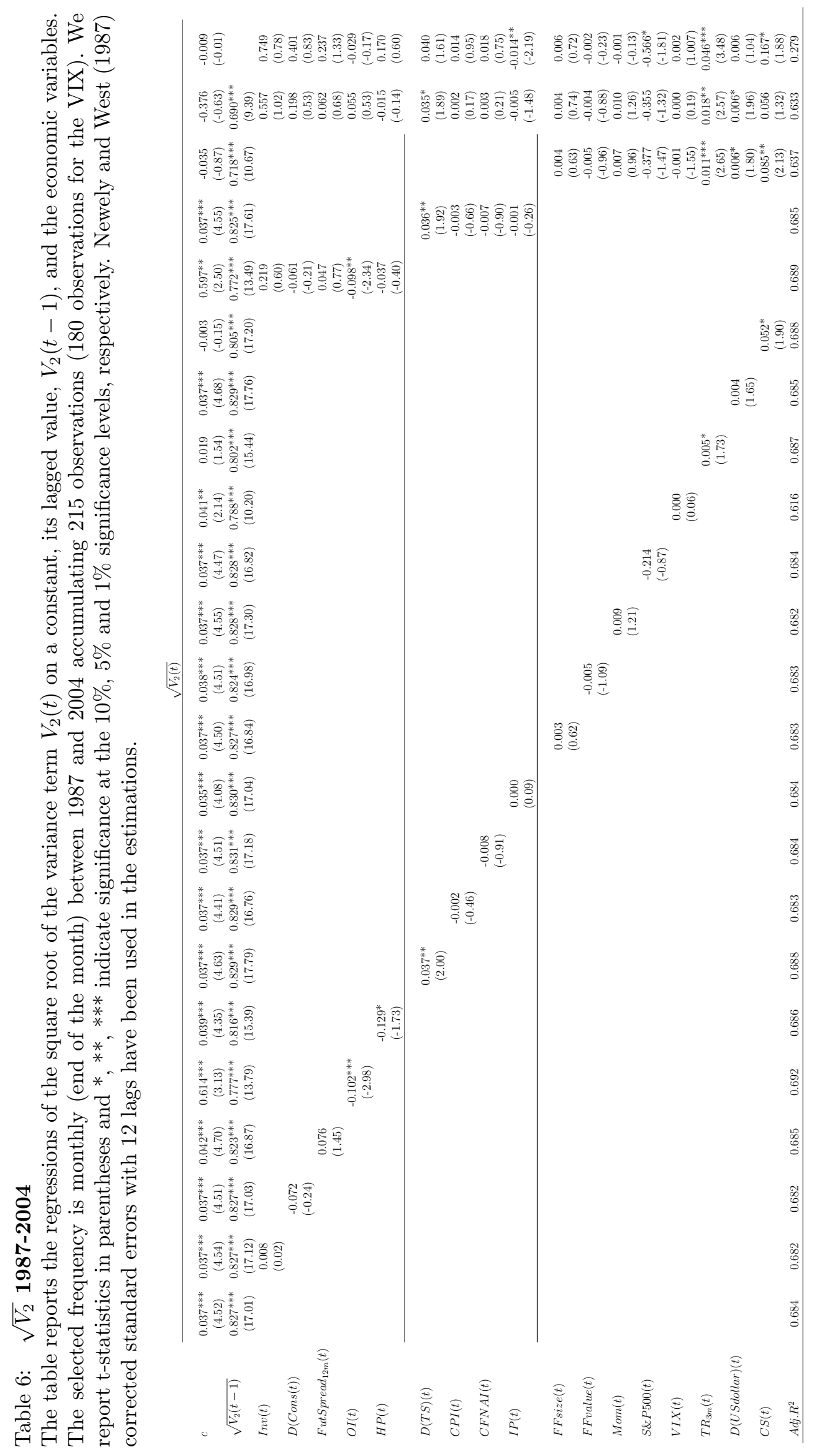




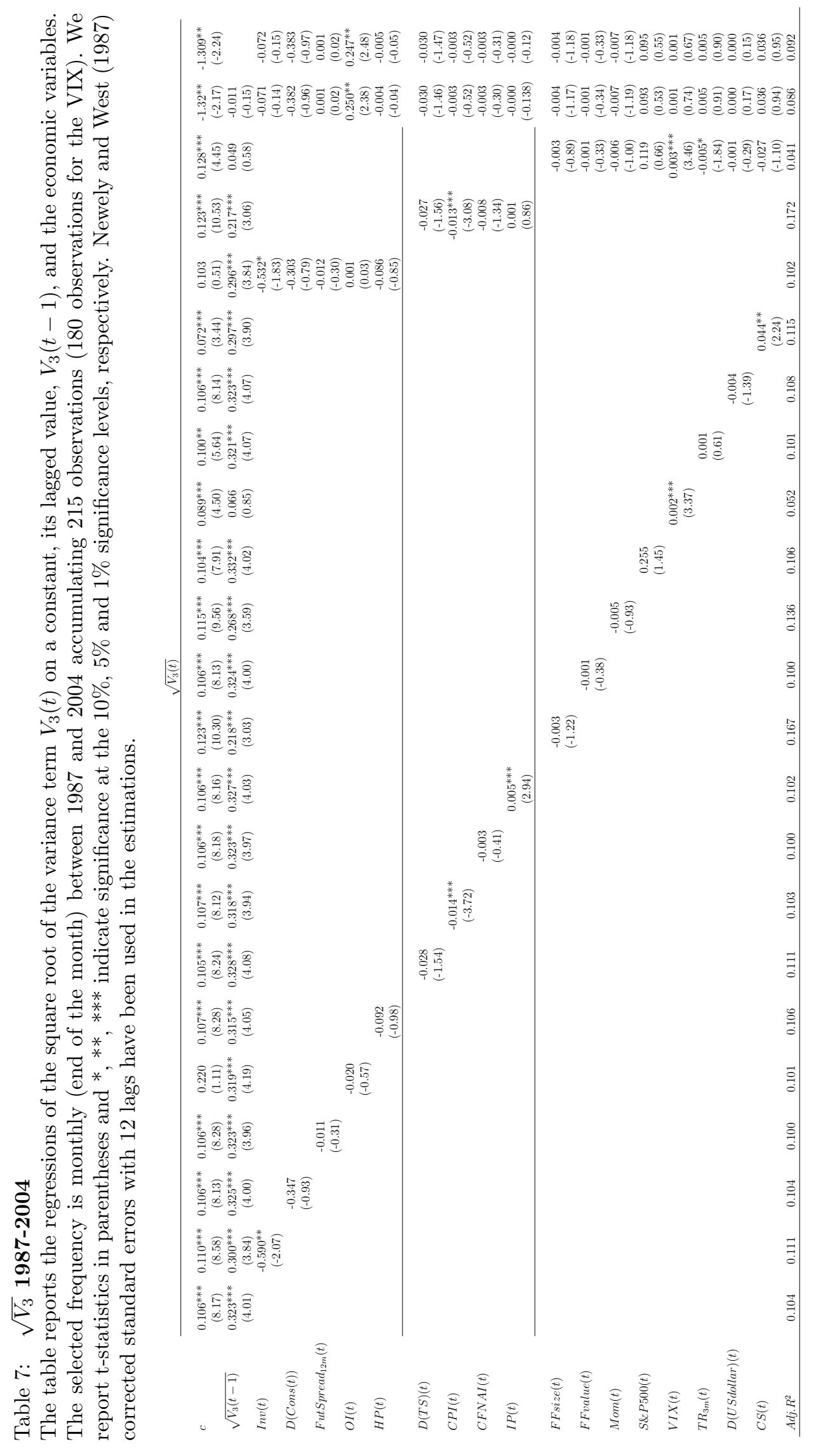




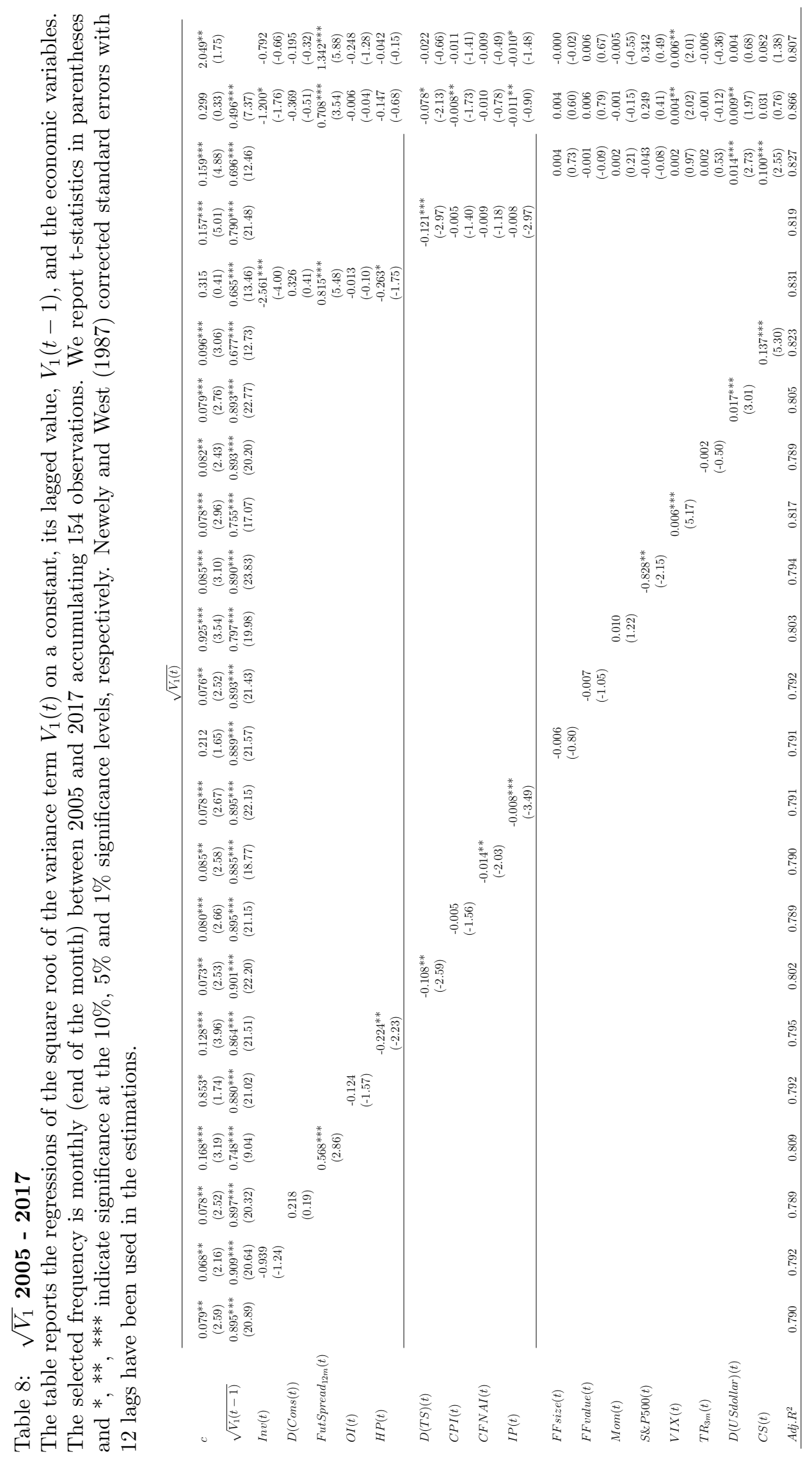




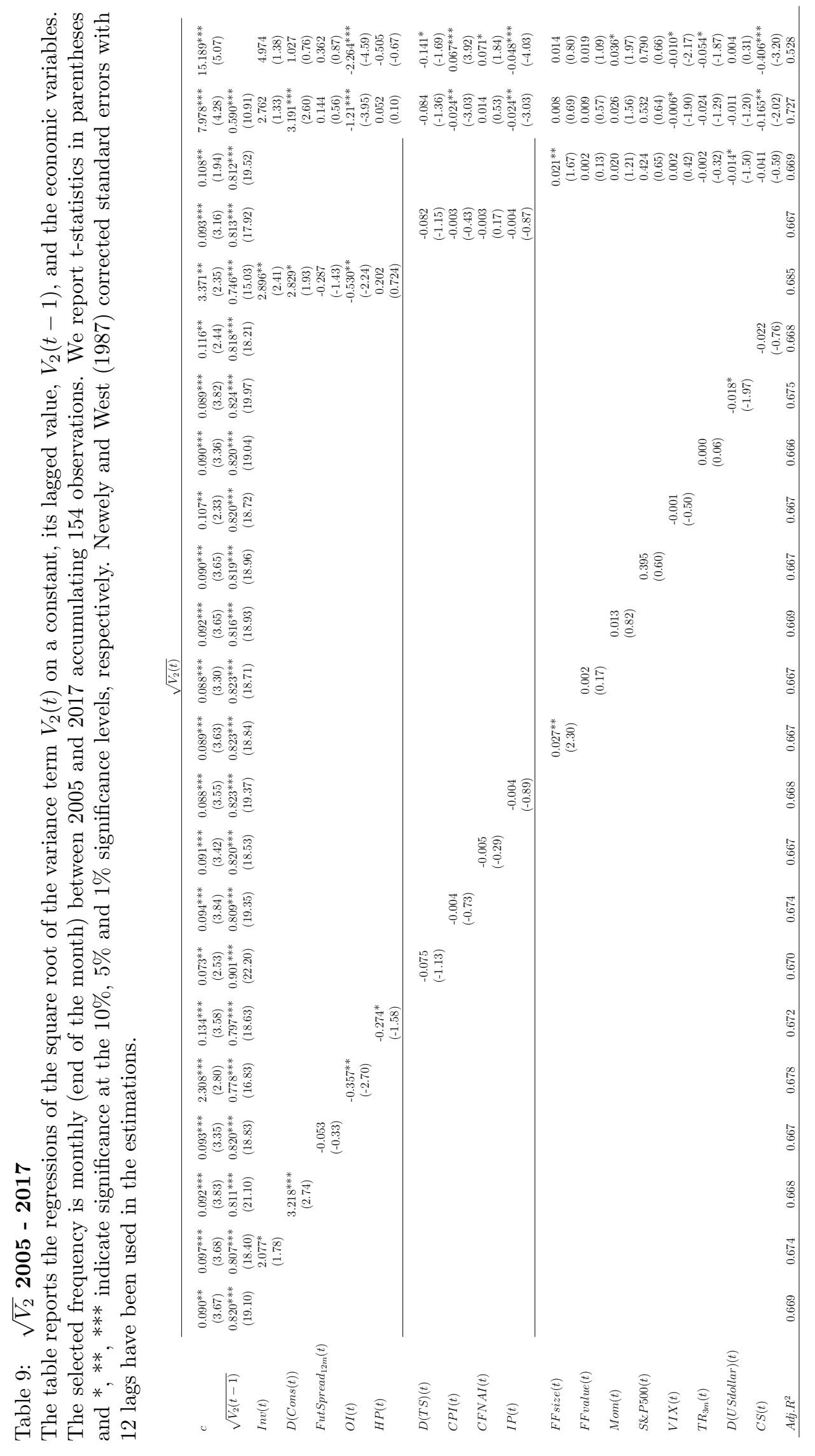




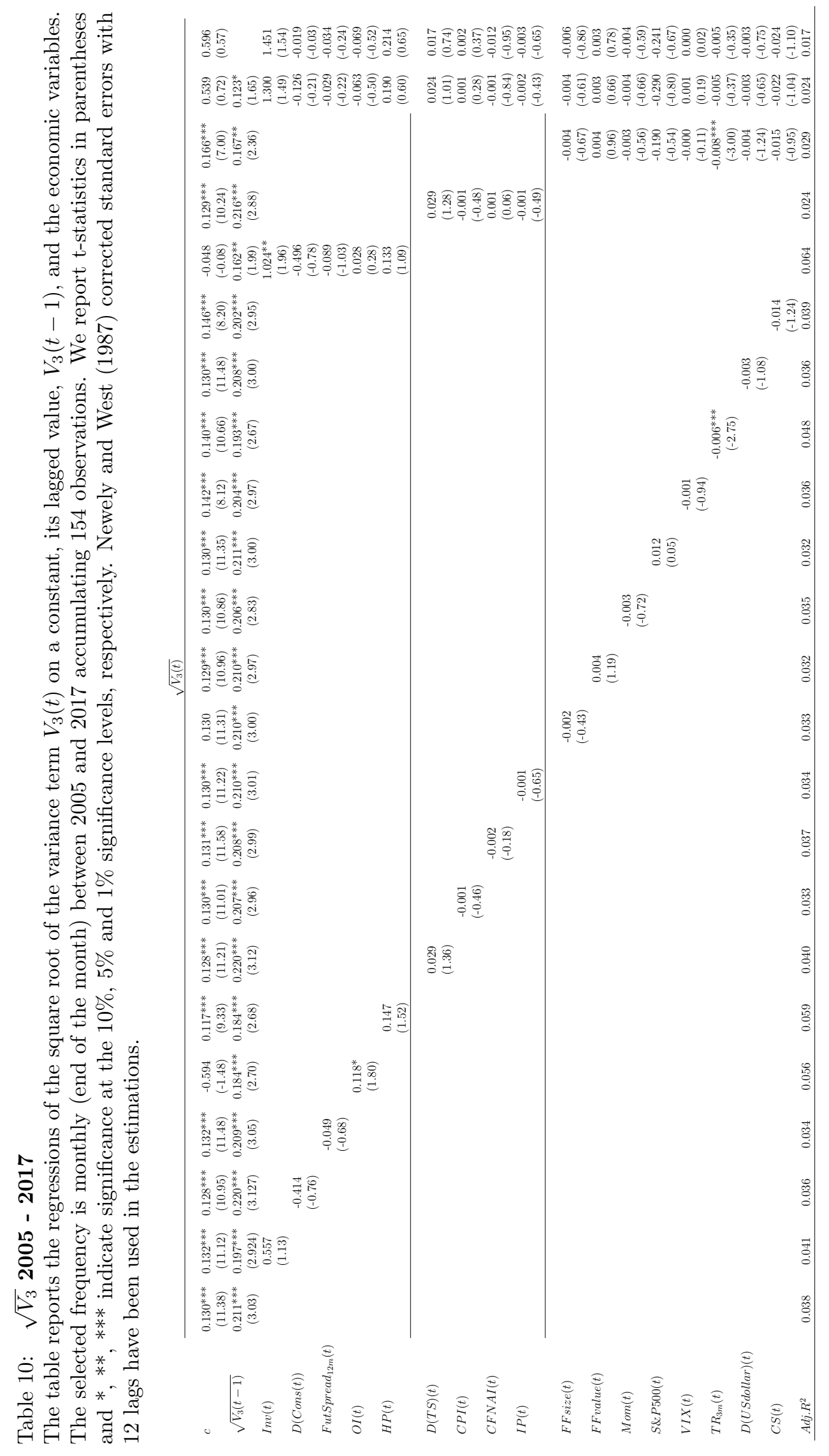




\section{References}

Alquist, R., Kilian, L., 2010. What do we learn from the price of crude oil futures? Journal of Applied Econometrics 25 (4), 539-573.

Anzuini, A., Pagano, P., Pisani, M., 2015. Macroeconomic effects of precautionary demand for oil. Journal of Applied Econometrics 30 (6), 968-986.

Arismendi, J., Back, J., Prokopczuk, M., Paschke, R., Rudolf, M., 2016. Seasonal stochastic volatility: Implications for the pricing of commodity options. Journal of Banking \& Finance 66, 53-65.

Arora, V., Tanner, M., 2013. Do oil prices respond to real interest rates? Energy Economics 36, $546-555$.

Arouri, M. E. H., Jouini, J., Nguyen, D. K., 2011. Volatility spillovers between oil prices and stock sector returns: Implications for portfolio management. Journal of International Money and Finance 30, 1387-1405.

Back, J., Prokopczuk, M., Rudolf, M., 2013. Seasonality and the evalation of commodity options. Journal of Banking \& Finance 37, 273-290.

Barone-Adesi, G., Whaley, R., 1987. Efficient analytic approximation of American option values. Journal of Finance 42, 301-320.

Basak, S., Pavlova, A., 2016. A model of financialization of commodities. Journal of Finance LXXI (4), 1511-1555.

Basu, D., Miffre, J., 2013. Capturing the risk premium of commodity futures: The role of hedging pressure. Journal of Banking \& Finance 37, 2652-2664.

Bauer, M., Mertens, T., 2018. Information in the yield curve about future recessions. FRBSF Economic Letters, Federal Reserve Bank of San Francisco.

Baum, C., Zerilli, P. Z., 2016. Jumps and stochastic volatility in crude oil futures prices using conditional moments of integrated volatility. Energy Economics 53, 175-181.

Baur, D. G., Dimpfl, T., 2018. The asymmetric return-volatility relationship of commodity prices. Energy Economics 76, 378-387.

Björk, T., Landén, C., Svensson, L., 2004. Finite dimensional realisations for stochastic volatility forward rate models. The Royal Society - Proceedings: Mathematical, Physical and Engineering Schiences 460 (2041), 53-83.

Black, F., 1976. The pricing of commodity contracts. Journal of Financial Economics 3, 167-179.

Casassus, J., Collin-Dufresne, P., 2005. Stochastic conveneience yield implied from commodity futures and interest rates. Journal of Finance 60, 2283-2331.

Casassus, J., Liu, P., Tang, K., 2013. Economic linkages, relative scarcity, and commodities futures returns. Review of Financial Studies 26 (5), 1324-1362. 
CEA, 2015. Explaining the U.S. petroleum consumption surprise. Council of Economic Advisors: Washington D.C.

URL https://www. whitehouse.gov/sites/default/files/docs/

Chen, Y., Turnovsky, S., Zivot, E., 2014. Forecasting inflation using commodity price aggregates. Journal of Econometrics 183, 117-134.

Cheng, B., Nikitopoulos, C., Schögl, E., 2018. Pricing of long-dated commodity derivatives: Do stochastic interest rates matter? Journal of Banking \& Finance 95, 148-166.

Cheng, I.-H., Xiong, W., 2014. Financialization of commodity markets. Annual Review of Financial Economics 6 (1), 419-441.

Chiang, I., Hughen, W. K., Sagi, J. S., 2015. Estimating oil risk factors using information from equity and derivatives markets. The Journal of Finance 70, 769-804.

Chiarella, C., Kang, B., Nikitopoulos, C. S., Tô, T., 2013. Humps in the volatility structure of the crude oil futures market: New evidence. Energy Economics 40, 989-1000.

Chiarella, C., Kang, B., Nikitopoulos, C. S., Tô, T., 2016. The return-volatility relation in commodity futures markets. Journal of Futures Markets 36 (2), 127-152.

Chiarella, C., Kwon, O., 2001. Forward rate dependent Markovian transformations of the HeathJarrow-Morton term structure model. Finance and Stochastics 5 (2), 237-257.

Christoffersen, P., Pan, X., 2018. Oil volatility risk and expected stock returns. Journal of Banking \& Finance 95, 5-26.

Cortazar, G., Lopez, M., Naranjo, L., 2017. A multifactor stochastic volatility model of commodity prices. Energy Economics 67, 182-201.

Da Fonseca, J., Ignatieva, K., 2019. Jump activity analysis for affine jump-diffusion models: Evidence from the commodity market. Journal of Banking \& Finance 99, 45-62.

Dai, Q., Singleton, K., 2000. Specification analysis of affine term structure models. Journal of Finance 55, 1943-1978.

de Roon, F. A., Nijman, T. E., Veld, C., 2000. Hedging pressure effects in futures markets. The Journal of Finance 55 (3), 1437-1456.

Del Negro, M., Giannone, D., Giannoni, M. P., Tambalotti, A., September 2018. Global trends in interest rates. Federal Reserve Bank of New York, staff Report No. 866.

Dempster, M. A. H., Medova, E., Tang, K., 2012. Determinants of oil futures prices and convenience yields. Quantitative Finance 12, 1795-1809.

Doran, J. S., Ronn, E. I., 2008. Computing the market price of volatility risk in the energy commodity market. Journal of Banking \& Finance 32, 2541-2552.

Duffie, D., 2001. Dynamic Asset Pricing Theory. Princeton, NJ:Princeton University Press.

Duffie, D., Kan, R., 1996. A yield-factor model of interest rates. Mathematical Finance 6 (4), 379-406. 
Engstrom, E., Sharpe, S., June 2018. (Don't fear) the yield curve. Feds notes, Federal Reserve System.

Estrella, A., Hardouvelis, G. A., 1991. The term structure as a predictor of real economic activity. Journal of Finance XLVI (2), 555-576.

Estrella, A., Mishkin, F., 1998. Predicting U.S. recessions: Financial variables are leading indicators. Review of Economics and Statistics 80, 45-61.

Fan, Y., Xu, J. H., 2011. What has been driven oil prices since 2000? A structural change perspective. Energy Economics 33, 1082-1094.

Fendel, R., Mai, N., Mohr, O., 2019. Predicting recessions using term spread at the zero lower bound: The case of the euro area. VoxEu.org, CEPR Policy.

Figuerola-Ferretti, I., Gilbert, C. L., 2008. Commonality in the LME aluminum and copper volatility processes through a FIGARCH lens. Journal of Futures Markets 28 (10), 935-962.

Gao, L., Hitzemann, S., Shaliastovich, I., Xu, L., 2017. Oil volatility risk. Working paper.

Geman, H., Ohana, S., 2009. Forward curves, scarcity and price volatility in oil and natural gas markets. Energy Economics 7 (4), 576-585.

Gorton, G., Rouwenhorst, K. G., 2006. Facts and fantasies about commodity futures. Financial Analysts Journal 62 (2), 47-68.

Hain, M., Uhrig-Homburg, M., Unger, N., 2018. Risk factors and their associated risk premia: An empirical analysis of the crude oil market. Journal of Banking \& Finance 95, 44-63.

Hamilton, J. D., Wu, J. C., 2014. Risk premia in crude oil futures prices. Journal of International Money and Finance 42, 9-37.

Heath, D., 2019. Macroeconomic factors in oil futures markets. Management Science 65 (9), 39494450.

Heston, S. L., 1993. A closed-form solution for options with stochastic volatility with applications to bond and currency options. Review of Financial Studies 6 (2), 327-343.

Hicks, J., 1939. Value and capital. Oxford University Press, Cambridge, U.K.

Hitzemann, S., 2016. Macroeconomic fluctuations, oil supply shocks, and equilibrium oil futures prices. Working paper.

Hollstein, F., Prokopczuk, M., Wuersig, C., 2019. Volatility term structures in commodity markets. Journal of Futures MarketsForthcoming.

Irwin, S., Sanders, D., 2011. Index funds, financialization, and commodity futures markets. Applied Economic Perspective and Policy 33, 1-31.

Keynes, J., 1930. The applied theory of money. Macmillan \& Co, London.

Kilian, L., 2009. Not all price shocks are alike: disentangling demand and supply shocks in the crude oil market. American Economic Review 99 (3), 1053-1069. 
Kilian, L., 2016. The impact of the shale oil revolution on U.S. oil and gasoline prices. Review of Environmental Economics and Policy 10 (2), 185-205.

Kilian, L., Hicks, B., 2013. Did unexpected strong economic growth caused the oil shock of 20032008? Journal of Forecasting 32 (5), 385-394.

Kilian, L., Murphy, D. P., 2014. The role of inventories and speculative trading in the global market for crude oil. Journal of Applied Econometrics 29 (3), 454-478, dOI: 10.1002/jae.2322.

Kilian, L., Park, C., 2009. The impact of oil price shocks on the U.S. stock market. International Economic Review 50 (4), 1267-1287.

Kogan, L., Livdan, D., Yaron, A., 2009. Oil futures prices in a production economy with investment constraints. The Journal of Finance 64 (3), 1345-1375.

Kolodziej, M., Kaufmann, R. K., Kulatilaka, N., Bicchetti, D., Maystre, N., 2014. Crude oil: Commodity or financial asset? Energy Economics 46, 216-223.

Li, B., 2018. Speculation, risk aversion, and risk premiums in the crude oil market. Journal of Banking and Finance, 1-18Https://doi.org/10.1016/j.jbankfin.2018.06.002.

Mollick, A. V., Assefa, T. A., 2013. U.S. stoch returns and oil prices: The tale from daily data and the 2008-2009 financial crisis. Energy Economics 36, 1-18.

Morana, C., 2013. Oil price dynamics, macro-finance interactions and the role of financial speculation. Journal of Banking and Finance 37, 206-226.

Nelson, C., Siegel, A., 1987. Parsimonious modelling of yield curves. Journal of Business 60, 473489.

Ng, V. K., Pirrong, S. C., 1994. Fundamentals and Volatility: Storage, Spreads, and the Dynamics of Metals Prices. Journal of Business 67 (2), 203-230.

Nikitopoulos, C., Squires, M., Thorp, S., Yeung, D., 2017. Determinants of the crude oil futures curve: Inventory, consumption and volatility. Journal of Banking \& Finance 84, 53-67.

Paschke, R., Prokopczuk, M., 2010. Commodity derivatives valuation with autoregressive moving average components in the price dynamics. Journal of Banking \& Finance 34, 2742-2752.

Pindyck, R. S., 2001. The dynamics of commodity spot and futures markets: A primer. Energy Journal 22 (3), 1-29.

Pindyck, R. S., 2004. Volatility and commodity price dynamics. Journal of Futures Markets 24 (11), 1029-1047.

Prokopczuk, M., Stancu, A., Symeonidis, L., 2019. The economic drivers of commodity market volatility. Journal of International Money and Finance 98, 102063.

Prokopczuk, M., Symeonidis, L., Wese Simen, C. W., 2017. Variance risk in commodity markets. Journal of Banking \& Finance 81, 136-149.

Prokopczuk, M., Wu, Y., 2016. The determinants of convenience yields. Working paper. 
Protter, P., 2004. Stochastic Integration and Differential Equations, 2nd Edition. Springer.

Robe, M. A., Wallen, J., 2016. Fundamentals, derivatives market information and oil price volatility. Journal of Futures Markets 36 (4), 317-344.

Schneider, D., Van Robays, I., Fratzscher, M., 2014. Oil prices, exchange rates and asset prices. Working paper series 1689, European Central Bank.

Schneider, L., Tavin, B., 2018. From the Samuelson volatility effect to a Samuelson correlation effect: An analysis of crude oil calendar spread options. Journal of Banking \& Finance 95, 185202.

Schwartz, E., 1997. The stochastic behaviour of commodity prices: Implications for valuation and hedging. Journal of Finance 52 (3), 923-973.

Schwartz, E., Smith, J., 2000. Short-term variations and long term dynamics in commodity prices. Management Science 46 (7), 893-911.

Schwartz, E. S., Trolle, A. B., 2010. Variance risk premia in energy commodities. Journal of Derivatives $17(3), 15-32$.

Silvennoinen, A., Thorp, S., 2013. Financialization, crisis and commodity correlation dynamics. Journal of International Financial Markets, Institutions and Money 24, 42-65.

Symeonidis, L., Prokopczuk, M., Brooks, C., Lazar, E., 2012. Futures basis, inventory and commodity price volatility: An empirical analysis. Economic Modelling 29, 2651-2663.

Szymanowska, M., De Roon, F., Nijman, T., Van den Goorbergh, R., 2014. An Anatomy of commodity futures risk premia. Journal of Finance 69 (1), 453-482.

Tang, K., Xiong, W., 2012. Index investment and the financialisation of commodities. Financial Analysts Journal 68, 54-74.

Trolle, A. B., Schwartz, E. S., 2009. Unspanned stochastic volatility and the pricing of commodity derivatives. Review of Financial Studies 22 (11), 4423-4461.

Wheelock, D. C., Wohar, M. E., 2009. Can the term spread predict output growth and recessions? A survey of the literature. Federal Reserve Bank of St. Louis Review 91 (5), 419-440. 